\title{
1 Ecosystem fluxes during drought and recovery in an experimental forest
}

2 Authors: Christiane Werner ${ }^{1 \dagger^{*}}$, Laura K. Meredith ${ }^{2,3 \dagger}$, S. Nemiah Ladd $^{1 \dagger}$, Johannes Ingrisch ${ }^{1,4}$,

3 Angelika Kübert ${ }^{1}$, Joost van Haren ${ }^{3,5}$, Michael Bahn $^{4}$, Kinzie Bailey ${ }^{2}$, Ines Bamberger ${ }^{1, \# 1}$, Matthias

4 Beyer $^{6}$, Daniel Blomdahl ${ }^{7}$, Joseph Byron ${ }^{8}$, Erik Daber ${ }^{1}$, Jason Deleeuw ${ }^{3}$, Michaela Dippold ${ }^{9,10}$,

5 Jane Fudyma ${ }^{11, \# 2}$, Juliana Gil-Loaiza ${ }^{2}$, Linnea K. Honeker ${ }^{3}$, Jia Hu², Jianbei Huang ${ }^{12}$, Thomas

6 Klüpfel $^{8}$, Jordan $\mathrm{Krechmer}^{13}$, Jürgen $\mathrm{Kreuzwieser}^{1}$, Kathrin Kühnhammer ${ }^{1,6}$, Marco M.

7 Lehmann ${ }^{14}$, Kathiravan Meeran ${ }^{4}$, Pawel K. Misztal ${ }^{7}$, Wei-Ren $\mathrm{Ng}^{3}$, Eva Pfannerstill ${ }^{8, \# 3}$, Giovanni

8 Pugliese ${ }^{1,8}$, Gemma Purser ${ }^{15}$, Joseph Roscioli ${ }^{12}$, Lingling Shi ${ }^{9,10}$, Malak Tfaily ${ }^{11,16,17}$, Jonathan

$9 \quad$ Williams ${ }^{8,18}$

11 Affiliations:

$12{ }^{1}$ Ecosystem Physiology, Faculty of Environment and Natural Resources, Albert-Ludwig-

13 University of Freiburg; Freiburg, Germany.

$14{ }^{2}$ School of Natural Resources and the Environment, University of Arizona; Tucson, AZ, USA.

$15 \quad{ }^{3}$ Biosphere 2, University of Arizona; Oracle, AZ, USA.

$16 \quad{ }^{4}$ Department of Ecology, University of Innsbruck; Innsbruck, Austria.

$17{ }^{5}$ Honors College, University of Arizona; Tucson, AZ, USA.

$18{ }^{6}$ Institute of Geoecology - Environmental Geochemistry, Technical University Braunschweig;

19 Braunschweig, Germany.

$20{ }^{7}$ Department of Civil, Architectural and Environmental Engineering, University of Texas at 21 Austin; Austin, TX, USA. 
$22{ }^{8}$ Department of Atmospheric Chemistry, Max Planck Institute for Chemistry; Mainz, Germany.

$23{ }^{9}$ Department of Biogeochemistry of Agroecosystems, University of Göttingen; Göttingen,

24 Germany.

$25{ }^{10}$ Geo-Biosphere Interactions, University of Tuebingen; Tuebingen, Germany

$26{ }^{11}$ Department of Environmental Science, University of Arizona; Tucson, AZ, USA.

$27{ }^{12}$ Max Planck Institute for Biogeochemistry; Jena, Germany.

$28 \quad{ }^{13}$ Aerodyne Research; Billerica, MA, USA.

$29{ }^{14}$ Forest Dynamics, Swiss Federal Institute for Forest, Snow and Landscape Research (WSL);

30 Birmensdorf, Switzerland.

$31{ }^{15}$ Centre for Ecology and Hydrology, University of Edinburgh; Edinburgh, UK.

$32{ }^{16}$ BIO5 Institute, The University of Arizona; Tucson, AZ, USA.

$33 \quad{ }^{17}$ Pacific Northwest National Laboratory; Richland, WA, USA.

$34 \quad{ }^{18}$ Energy, Environment and Water Research Center, The Cyprus Institute; Nicosia, Cyprus.

35 Current affiliation:

$36 \quad{ }^{\# 1}$ Atmospheric Chemistry Group, University of Bayreuth (BayCEER), Germany

$37 \quad{ }^{\# 2}$ Department of Land, Air and Water Resources, University of California Davis; Davis CA, USA.

$38{ }^{\# 3}$ University of California at Berkeley, Department of Environmental Science, Policy and

39 Management, Berkeley, USA.

$40 \quad *$ Correspondence to: $\underline{\text { c.werner@ cep.uni-freiburg.de }}$

$41 \quad$ †equal contributions 
Abstract:

Severe droughts endanger ecosystem functioning worldwide. We investigated how drought impacts carbon and water fluxes and soil-plant-atmosphere interactions by tracing ${ }^{13} \mathrm{CO}_{2}$ - and deep-water ${ }^{2} \mathrm{H}_{2} \mathrm{O}$ label-pulses and volatile organic compounds (VOCs) in an enclosed experimental rainforest. Ecosystem dynamics were driven by different plant functional group responses to drought. Drought-sensitive canopy trees dominated total fluxes, but also responded most to topsoil drying. Although all canopy-forming trees accessed deep-water, these reserves were spared until late drought. Belowground carbon transport slowed down, yet allocation of fresh carbon to VOCs remained high. Atmospheric VOC composition reflected increasing stress responses and dynamic soil-plant-atmosphere interactions, potentially impacting atmospheric chemistry and climate feedbacks. These interactions and distinct functional group strategies thus modulate drought impacts and ecosystem susceptibility to climate change.

\section{One Sentence Summary:}

Plant functional adaptations, water use strategies, and soil interactions determine forest drought impact and recovery

Climate change is increasing the frequency and severity of droughts worldwide, threatening ecosystem functioning (1) with the potential to strongly diminish carbon sequestration (1-3). This is particularly concerning for large tropical forests, which are a major component of the terrestrial carbon sink (4). Much of the sink capacity of tropical forests can be lost after severe droughts (5), and their overall ability to assimilate and retain carbon is projected to further decline under future 
warming scenarios (6). Moreover, tropical forests represent a main source of atmospheric biogenic volatile organic compounds (VOCs) (7), which may amplify under heat and drought (8) causing climate feedbacks through ozone, organic aerosol formation (9), and aerosol-radiation interaction (10). While large-scale changes in carbon and water fluxes through ecosystems can be observed through monitoring networks (11), many of the mechanisms underpinning these drought-induced dynamics remain unclear (12). Specific knowledge gaps include (i) how total ecosystem susceptibility and resilience are shaped by different plant water use strategies (13) and deep-water access (12), (ii) how drought-stressed vegetation adjusts carbon investments into maintenance and protection (14) including the production of $\operatorname{VOCs}(8,15)$, and (iii) how interactions and feedbacks between different components modulate ecosystem dynamics (16-18).

The Biosphere 2 Tropical Rainforest (19) (Fig S1-S3) is an enclosed experimental ecosystem where interactions among individual ecosystem components in response to environmental changes can be mechanistically studied (e.g. 20,21). As part of the Biosphere 2 Water Atmosphere and Life Dynamics (B2WALD) campaign (Fig. S4) we imposed a 9.5-week drought on this system (19) to determine mechanisms responsible for overall changes in ecosystem-scale water and carbon dynamics in response to drought and recovery. Drought propagated dynamically through different forest strata (Fig 1). Atmospheric drought (vapor pressure deficit; VPD) increased rapidly in the sunlit canopy, while the understory was buffered by canopy shading, and did not reach maximum values until late in severe drought (Fig. 1A). The soil also dried out sequentially, with rapid topsoil drying during early drought. The deepest soil layers maintained high moisture until late into severe drought. 
87 The largest decline in ecosystem water and carbon fluxes coincided with increasing VPD and topsoil drying during early drought (Fig. 1B, C). Evapotranspiration (ET), ecosystem respiration $\left(\mathrm{R}_{\mathrm{eco}}\right)$, and gross primary productivity (GPP) declined relative to pre-drought values by $58 \%, 50 \%$, and $47 \%$, respectively. Each of these fluxes decreased further during severe drought, but at lower rates (to $30 \%, 27 \%$, and $32 \%$ of pre-drought values, respectively). Net ecosystem exchange of carbon $\left(\mathrm{NEE}=\mathrm{GPP}-\mathrm{R}_{\mathrm{eco}}\right)$, was buffered by concomitant reductions in GPP and $\mathrm{R}_{\mathrm{eco}}$ during early drought. The forest remained a small carbon sink, despite the $79 \%$ reduction in GPP under severe drought.

Daytime concentrations of atmospheric VOCs also changed dynamically in response to drought (Fig. 1E). These changes were not uniform among compounds, and concentrations of distinct VOCs increased sequentially in response to drought: first isoprene, then monoterpenes, and finally hexanal. These VOCs play important roles in leaf stress tolerance and signaling $(22,23)$, and hexanal has also been associated with drought-induced leaf senescence (24).

Net uptake of isoprene and monoterpenes by the soil (Fig. 1F) was influenced by both overlying atmospheric concentrations and soil moisture. During drought, the concentration-normalized soil uptake capacity of monoterpenes increased relative to isoprene (Fig. S5). This indicates greater persistence of monoterpene scavenging by soils under drought when plant monoterpene emissions were highest. Together, interactions between plants and soil led to distinct patterns in the relative abundance of atmospheric VOC concentrations as drought progressed (Fig. 1E), serving as a diagnostic indicator of ecosystem drought stress (24), with isoprene indicating the onset of ET and GPP reduction, and hexanal their final decline under severe drought.

The structured re-addition of moisture to the ecosystem, first in groundwater layers and then surface soil, released ecosystem components from drought with different temporal dynamics. The 
110 vegetation moderately responded to the addition of deep water, resulting in a slow increase in GPP

111 and ET. Top soil moisture, soil respiration and soil VOC dynamics did not respond, indicating that

112 hydraulic lift (29) was not sufficient to relieve the system from drought. In contrast, soil respiration

113 and VOC uptake increased immediately upon rain rewet (Fig. 1). Within 3 months of drought

114 release, ET values had returned to pre-drought levels, but carbon fluxes displayed pronounced

115 legacy effects, with $\mathrm{R}_{\text {eco }}$ and GPP recovering to $45 \%$ and $90 \%$ of pre-drought values, respectively.

116 The vegetation displayed highly diverse drought responses among and within species, driven by

117 the interplay of species-specific drought adaptations and differences in microclimate conditions.

118 We identified four major functional response-types: drought-tolerant and drought-sensitive plants

119 of either large, canopy forming trees or understory species (Table S1).

120 Drought-sensitive canopy trees dominated total ecosystem water fluxes under pre-drought 121 conditions, but had the largest reductions in sap flow coincident with upper soil drying in early

122 drought (Fig. 2), when leaf senescence and substantial leaf shedding was observed. Leaf aging and 123 shedding occured in all species to different degrees but leaf shedding was higher in drought124 sensitive trees, particularly in Clitoria fairchildiana (approximately 25\% leaf loss). In contrast, 125 drought-tolerant canopy trees had significantly lower water fluxes than their drought-sensitive counterparts under non-stressed conditions $(\mathrm{p}<0.001)$ and had more moderate reductions in sap

127 flow with no visible signs of senescence during early drought. Water fluxes of understory plants were an order of magnitude lower than those of tall trees (Fig.

130 2). Drought-sensitive understory plants displayed the strongest decline of predawn and midday

131 leaf water potential, indicating severe stress. Drought-tolerant understory plants showed only 132 modest signs of drought stress. The presence of a robust understory in locations where shading 
133 buffered changes in VPD and temperature helped maintain ecosystem functioning at reduced

134 levels into the severe drought. Thus, an intact forest canopy can provide important beneficial forest microclimate, with an important role in buffering the long-term effects of climate warming (25). Overall, total plant water flux from drought-tolerant plants in both strata became more important during drought, with their combined contribution increasing from $15 \%$ (pre-drought) to $35 \%$ (severe drought) (Fig. 2D). In contrast, drought-sensitive canopy trees dominated the total water flux (74\% during pre-drought; 57\% during severe drought).

The swift reduction in water use by drought-sensitive canopy trees (Fig. 2A) preceded deep soil drying by several weeks (Figs. 1A). Contrary to the expectation that trees would use all accessible water before reducing leaf area and carbon-fueled activities, ${ }^{2} \mathrm{H}$-enrichment of transpiration following ${ }^{2} \mathrm{H}_{2} \mathrm{O}$-tracer addition to the deep soil during severe drought demonstrated that all canopy trees in both the drought-sensitive and drought-tolerant groups had access to deep-water (Fig. 3). Despite the accessibility to roots, these deep-water reserves were largely spared until severe drought (Fig. 1A). Additionally, despite strong drought stress, there was a pronounced lag between uptake and transpiration of deep-water (Fig. 3A). The peak of ${ }^{2} \mathrm{H}$-enriched transpiration only

148 occurred after the deep soil had dried following the ${ }^{2} \mathrm{H}$-labeled water addition, and when unlabeled precipitation was once again available in the forest. The several week delay of maximum transpired

$150 \delta^{2} \mathrm{H}$ values indicates that stem water residence time was unexpectedly long, with the quickest 151 response in drought-sensitive and the greatest delay for drought-tolerant canopy trees. This is 152 consistent with low sap flow velocities of drought-tolerant trees (Fig. 2), and with the recovery of tree water content in stems in drought-sensitive species (Fig. 3B). drought resistance, these adaptations delayed recovery following the return of rain by slowing the 
156

157

158

159

160

161

162

163

164

165

166

167

168

169

flux of water through the ecosystem. Even after eight weeks, the total canopy water flux had only recovered to 63\% of pre-drought values (Fig. 2D). Drought-sensitive species contributed to a rapid resumption of ecosystem function upon rewet, but at reduced rates (Fig. 2A). Specifically, legacy effects were caused by persistent structural changes in drought-sensitive trees (loss of hydraulic conductivity and leaves). In contrast, drought-tolerant species did not exhibit these structural changes and became relatively more important to ecosystem function during drought, contributing to overall ecosystem resistance. However, their generally slower responses limited the contribution of drought-tolerant trees during recovery.

In addition to reducing water and $\mathrm{CO}_{2}$ fluxes through the ecosystem, the rate at which assimilated carbon moves through ecosystems can decline under drought $(14,26,27)$. We traced carbon allocation from leaves to stems and soils with whole-ecosystem ${ }^{13} \mathrm{CO}_{2}$ pulse-chase experiments (Fig. 4; 19). Reduced carbon assimilation under drought resulted in lower ecosystem ${ }^{13} \mathrm{C}$-uptake (37\% of the pre-drought, Fig. $4 \mathrm{H}$ ), despite adding twice as much ${ }^{13} \mathrm{C}$-label to the atmosphere under drought (Fig. 4A). Although ecosystem assimilation declined under drought, bulk leaf material became more ${ }^{13} \mathrm{C}$-enriched (Fig. 4B, C; Table S2), with a greater increase for drought-sensitive plants. Likewise, $\delta^{13} \mathrm{C}$ of leaf respiration was higher following the drought ${ }^{13} \mathrm{CO}_{2}$ pulse compared to pre-drought, with greater increases for canopy trees relative to understory, and for droughtsensitive plants relative to drought-tolerant (Fig. 4B, C; Table S3). Although metabolic activity was reduced, the fresh carbon was preferentially used as respiratory substrate.

Belowground ${ }^{13} \mathrm{C}$-transport was slower under drought, as indicated by $\delta^{13} \mathrm{C}$ values of stem respiration, while the ${ }^{13} \mathrm{C}$ residence time in stems increased (Fig. 4D, I; Table S3; S4). ${ }^{13} \mathrm{C}-$ enrichment of fine roots was ultimately similar following both label pulses (Fig. 4E). However, 
179 soil respiration was less ${ }^{13} \mathrm{C}$-enriched during the drought, suggesting that ${ }^{13} \mathrm{C}$ was preferentially 180 used to build root biomass, rather than for root respiration or exudates.

Despite reduced ecosystem carbon uptake and total VOC emissions, plants continued to allocate a

182 similar proportion of fresh carbon to de novo VOC synthesis, as ${ }^{13} \mathrm{C}$-incorporation into both isoprene and monoterpenes remained high (Fig. 4F, G). Maintaining carbon allocation into VOC synthesis demonstrates the fundamental role of these compounds in protecting plants from heat stress and photooxidative damage that can be caused by reduced stomatal conductance and Cmetabolism under drought (8).

The B2WALD experiment demonstrates the importance of plant functional groups for understanding ecosystem responses to drought (Fig. S7) (12, 28-30). Different hydraulic strategies of distinct plant functional groups and their changing proportional contribution determine the overall magnitude of reduction in ecosystem fluxes as drought progressed (Fig. 2, 4). Moreover, plant adaptations determine the velocity and residence time of water and carbon in different plant organs such as stems and leaves (Fig. 2-4). Therefore, distinct plant hydraulic strategies can increase the resistance to drought: the presence of drought-tolerant trees buffered the drought decline in ecosystem fluxes, while the fast restriction of water use in drought-sensitive trees lowered the risk of detrimental depletion of soil water sources, which improves the likelihood of withstanding prolonged droughts. The degree to which ecosystems are able to resist extreme droughts will impact their functioning upon the return to more favorable hydrologic regimes. In 199 our study, the drought's legacy was visible as the carbon sink capacity of the forest remained suppressed months after the cessation of drought (Fig. 1), partly due to the physiological and structural responses of drought-sensitive canopy trees. This has important implications for coupled 
202 climate-vegetation Earth system models, which will miss significant processes if distinct plant 203 hydraulic responses are not considered $(12,31)$.

204 Notably, the forest flux dynamics were tightly coupled to shallow soil processes, as the largest 205 decrease in ecosystem fluxes corresponded to early dry-down of topsoil moisture (Fig. 1, S8), 206 despite access to deep-water reserves in all canopy trees (Fig. 3). Plants can dynamically adjust 207 their root water uptake depth via active regulation of conductivity in the rooting zone (32), however most roots are allocated in the upper soil, where they mediate important soil-plant interactions in 209 the rhizosphere via carbon and nutrient exchange (18). Drying of this zone induced significant 210 down-regulation of transpiration, particularly in drought-sensitive canopy trees, indicating that 211 changes in critical zones trigger drought responses, rather than total accessible water. Reductions 212 in transpiration and assimilation were associated with delayed transport of carbon belowground 213 (Fig. 4), and with a likely reduction in fresh carbon allocated to soil respiration (Fig. 1, 4). 214 Although phloem-transport in these trees was delayed by drought, its magnitude was not reduced 215 (14). Additionally, the rate at which water moved from deep soils to the leaves of drought-stressed 216 deep-rooted trees was unexpectedly slow (33), with especially long residence times for stem water 217 in drought-tolerent canopy trees (>55 days, Fig. 3). Incorporation of different plant hydraulic 218 strategies and dynamics response to sequential soil drying in models may be critical for accurately 219 simulating the magnitude and timing of vegetation-driven changes in ecosystem fluxes and landatmosphere feedbacks under climate change $(16,31)$. Additionally, Earth system models need to account for coupled plant-soil interactions, which not only change the movement of carbon and water through ecosystems, but can also impact atmosphere chemistry. In the B2WALD drought experiment, plant-soil interactions led to a distinct 224 pattern in atmospheric VOC concentrations, which tracked the increase in drought severity (Fig. 


\section{References}

1. G. B. Bonan, Forests and climate change: forcings, feedbacks, and the climate benefits of forests. Science. 320, 1444-1449 (2008), doi:10.1126/science.1155121.

2. M. Reichstein et al., Climate extremes and the carbon cycle. Nature. 500, 287-295 (2013), doi:10.1038/nature12350.

3. A. Bastos et al., Direct and seasonal legacy effects of the 2018 heat wave and drought on European ecosystem productivity. Science advances. 6, eaba2724 (2020), doi:10.1126/sciadv.aba2724.

4. Y. Pan et al., A large and persistent carbon sink in the world's forests. Science. 333, 988-993 (2011), doi:10.1126/science.1201609.

5. J.-P. Wigneron et al., Tropical forests did not recover from the strong 2015-2016 El Niño event. Science advances. 6, eaay4603 (2020), doi:10.1126/sciadv.aay4603.

6. W. Hubau et al., Asynchronous carbon sink saturation in African and Amazonian tropical forests. Nature. 579, 80-87 (2020), doi:10.1038/s41586-020-2035-0.

7. A. B. Guenther et al., The Model of Emissions of Gases and Aerosols from Nature version 2.1 (MEGAN2.1): an extended and updated framework for modeling biogenic emissions. Geosci. Model Dev. 5, 1471-1492 (2012), doi:10.5194/GMD-5-1471-2012.

8. F. Loreto, J.-P. Schnitzler, Abiotic stresses and induced BVOCs. Trends in plant science. 15, 154-166 (2010), doi:10.1016/j.tplants.2009.12.006.

9. A. Arneth et al., Terrestrial biogeochemical feedbacks in the climate system. Nature Geosci. 3, 525-532 (2010), doi:10.1038/ngeo905.

10. N. Unger, On the role of plant volatiles in anthropogenic global climate change. Geophys. Res. Lett. 41, 85638569 (2014), doi:10.1002/2014GL061616.

11. H. Chu, D. D. Baldocchi, R. John, S. Wolf, M. Reichstein, Fluxes all of the time? A primer on the temporal representativeness of FLUXNET. J. Geophys. Res. 122, 289-307 (2017), doi:10.1002/2016JG003576.

12. W. R. L. Anderegg et al., Hydraulic diversity of forests regulates ecosystem resilience during drought. Nature. 561, 538-541 (2018), doi:10.1038/s41586-018-0539-7.

13. T. J. Brodribb, J. Powers, H. Cochard, B. Choat, Hanging by a thread? Forests and drought. Science. 368, 261266 (2020), doi:10.1126/science.aat7631.

14. H. Hartmann, M. Bahn, M. Carbone, A. D. Richardson, Plant carbon allocation in a changing world - challenges and progress: introduction to a Virtual Issue on carbon allocation: Introduction to a virtual issue on carbon allocation. New Phytol. 227, 981-988 (2020), doi:10.1111/nph.16757.

15. J. K. Holopainen, J. Gershenzon, Multiple stress factors and the emission of plant VOCs. Trends in plant science. 15, 176-184 (2010), doi:10.1016/j.tplants.2010.01.006.

16. N. M. Levine et al., Ecosystem heterogeneity determines the ecological resilience of the Amazon to climate change. PNAS. 113, 793-797 (2016), doi:10.1073/pnas.1511344112. 
17. J. Joseph et al., Rhizosphere activity in an old-growth forest reacts rapidly to changes in soil moisture and shapes whole-tree carbon allocation. PNAS. 117, 24885-24892 (2020), doi:10.1073/pnas.2014084117.

18. F. I. Pugnaire et al., Climate change effects on plant-soil feedbacks and consequences for biodiversity and functioning of terrestrial ecosystems. Science advances. 5, eaaz1834 (2019), doi:10.1126/sciadv.aaz1834.

19. C. Werner, et al., Supplementary Materialsfor Ecosystem fluxes during drought and recovery in an experimental forest. Science.

20. U. Rascher et al., Functional diversity of photosynthesis during drought in a model tropical rainforest - the contributions of leaf area, photosynthetic electron transport and stomatal conductance to reduction in net ecosystem carbon exchange. Plant Cell Environ. 27, 1239-1256 (2004), doi:10.1111/j.1365-3040.2004.01231.x.

21. M. N. Smith et al., Empirical evidence for resilience of tropical forest photosynthesis in a warmer world. Nat. Plants. 6, 1225-1230 (2020), doi:10.1038/s41477-020-00780-2.

22. R. K. Monson, S. M. Weraduwage, M. Rosenkranz, J.-P. Schnitzler, T. D. Sharkey, Leaf isoprene emission as a trait that mediates the growth-defense tradeoff in the face of climate stress. Oecologia (2021), doi:10.1007/s00442-020-04813-7.

23. C. Werner, L. Fasbender, K. M. Romek, A. M. Yáñez-Serrano, J. Kreuzwieser, Heat Waves Change Plant Carbon Allocation Among Primary and Secondary Metabolism Altering $\mathrm{CO}_{2}$ Assimilation, Respiration, and VOC Emissions. Front. Plant Sci. 11 (2020), doi:10.3389/fpls.2020.01242.

24. K. J. Jardine et al., Green Leaf Volatile Emissions during High Temperature and Drought Stress in a Central Amazon Rainforest. Plants. 4, 678-690 (2015), doi:10.3390/plants4030678.

25. F. Zellweger et al., Forest microclimate dynamics drive plant responses to warming. Science. 368, 772-775 (2020), doi:10.1126/science.aba6880.

26. D. Epron et al., Pulse-labelling trees to study carbon allocation dynamics: a review of methods, current knowledge and future prospects. Tree Physiol. 32, 776-798 (2012), doi:10.1093/treephys/tps057.

27. N. K. Ruehr et al., Drought effects on allocation of recent carbon: from beech leaves to soil $\mathrm{CO}_{2}$ efflux. The New phytologist. 184, 950-961 (2009), doi:10.1111/j.1469-8137.2009.03044.x.

28. J. Aguirre-Gutiérrez et al., Long-term droughts may drive drier tropical forests towards increased functional, taxonomic and phylogenetic homogeneity. Nat Commun. 11, 3346 (2020), doi:10.1038/s41467-020-16973-4.

29. J. Aguirre-Gutiérrez et al., Drier tropical forests are susceptible to functional changes in response to a long-term drought. Ecol Letters. 22, 855-865 (2019), doi:10.1111/ele.13243.

30. S. Haberstroh et al., Nonlinear plant-plant interactions modulate impact of extreme drought and recovery on a Mediterranean ecosystem. New Phytol. 231, 1784-1797 (2021), doi:10.1111/nph.17522.

31. W. R. L. Anderegg, A. T. Trugman, D. R. Bowling, G. Salvucci, S. E. Tuttle, Plant functional traits and climate influence drought intensification and land-atmosphere feedbacks. PNAS. 116, 14071-14076 (2019), doi:10.1073/pnas.1904747116.

32. M. Dubbert, C. Werner, Water fluxes mediated by vegetation: emerging isotopic insights at the soil and atmosphere interfaces. New Phytol. 221, 1754-1763 (2019), doi:10.1111/nph.15547.

33. M. Sprenger et al., The Demographics of Water: A Review of Water Ages in the Critical Zone. Rev. Geophys. 57, 800-834 (2019), doi:10.1029/2018RG000633.

34. E. Y. Pfannerstill et al., Total OH Reactivity Changes Over the Amazon Rainforest During an El Niño Event. Front. For. Glob. Change. 1 (2018), doi:10.3389/ffgc.2018.00012.

35. U. Pöschl et al., Rainforest aerosols as biogenic nuclei of clouds and precipitation in the Amazon. Science. 329, 1513-1516 (2010), doi:10.1126/science.1191056.

\section{References for supplement}

36. T. C. Taylor et al., Isoprene emission structures tropical tree biogeography and community assembly responses to climate. New Phytol. 220, 435-446 (2018), doi:10.1111/nph.15304.

37. L. S. Leigh, T. Burgess, B. D. Marino, Y. D. Wei, Tropical rainforest biome of Biosphere 2: Structure, composition and results of the first 2 years of operation. Ecological Engineering. 13, 65-93 (1999), doi:10.1016/S0925-8574(98)00092-5.

38. B. Osmond et al., Changing the way we think about global change research: scaling up in experimental ecosystem science. Glob Change Biol. 10, 393-407 (2004), doi:10.1111/j.1529-8817.2003.00747.x.

39. E. Pegoraro et al., The effect of elevated atmospheric CO2 and drought on sources and sinks of isoprene in a temperate and tropical rainforest mesocosm. Global Change Biology. 11, 1234-1246 (2005), doi:10.1111/j.1365-2486.2005.00986.x. 
40. E. Pegoraro, A. Rey, L. Abrell, J. Vanharen, G. H. Lin, Drought effect on isoprene production and consumption in Biosphere 2 tropical rainforest. Global Change Biology. 12, 456-469 (2006).

41. J. Evaristo et al., Characterizing the Fluxes and Age Distribution of Soil Water, Plant Water, and Deep Percolation in a Model Tropical Ecosystem. Water Resour. Res. 55, 3307-3327 (2019), doi:10.1029/2018WR023265.

42. J. L. M. van Haren et al., Drought-induced nitrous oxide flux dynamics in an enclosed tropical forest. Global Change Biol. 11, 1247-1257 (2005), doi:10.1111/j.1365-2486.2005.00987.x.

43. H. J. Scott, Characteristics of soils in the tropical rainforest biome of Biosphere 2 after 3 years. Ecological Engineering. 13, 95-106 (1999), doi:10.1016/S0925-8574(98)00093-7.

44. M. Finn, The mangrove mesocosm of Biosphere 2: Design, establishment and preliminary results. Ecological Engineering. 6, 21-56 (1996), doi:10.1016/0925-8574(95)00050-х.

45. P. F. Scholander, E. D. Bradstreet, E. A. Hemmingsen, H. T. Hammel, Sap Pressure in Vascular Plants: Negative hydrostatic pressure can be measured in plants. Science (New York, N.Y.). 148, 339-346 (1965), doi:10.1126/science.148.3668.339.

46. D. J. Barrett, J. T. Hatton, J. E. Ash, M. C. Ball, Evaluation of the heat pulse velocity technique for measurement of sap flow in rainforest and eucalypt forest species of south-eastern Australia. Plant Cell Environ. 18, 463-469 (1995), doi:10.1111/j.1365-3040.1995.tb00381.x.

47. F. C. Meinzer, B. J. Bond, J. M. Warren, D. R. Woodruff, Does water transport scale universally with tree size? Funct Ecology. 19, 558-565 (2005), doi:10.1111/j.1365-2435.2005.01017.x.

48. S. D. Wullschleger, A. W. King, Radial variation in sap velocity as a function of stem diameter and sapwood thickness in yellow-poplar trees. Tree Physiol. 20, 511-518 (2000), doi:10.1093/treephys/20.8.511.

49. T. Gebauer, V. Horna, C. Leuschner, Variability in radial sap flux density patterns and sapwood area among seven co-occurring temperate broad-leaved tree species. Tree Physiol. 28, 1821-1830 (2008), doi:10.1093/treephys/28.12.1821.

50. M. Altaf Arain, W. James Shuttleworth, B. Farnsworth, J. Adams, O. Lutfi Sen, Comparing micrometeorology of rain forests in Biosphere-2 and Amazon basin. Agricultural and Forest Meteorology. 100, 273-289 (2000), doi:10.1016/S0168-1923(99)00153-7.

51. L. A. Pangle et al., The Landscape Evolution Observatory: A large-scale controllable infrastructure to study coupled Earth-surface processes. Geomorphology. 244, 190-203 (2015), doi:10.1016/j.geomorph.2015.01.020.

52. A. L. Buck, New Equations for Computing Vapor Pressure and Enhancement Factor. J. Appl. Meteor. 20, 15271532 (1981), doi:10.1175/1520-0450(1981)020.

53. L. Fasbender, A. M. Yáñez-Serrano, J. Kreuzwieser, D. Dubbert, C. Werner, Real-time carbon allocation into biogenic volatile organic compounds (BVOCs) and respiratory carbon dioxide (CO2) traced by PTR-TOF-MS, 13CO2 laser spectroscopy and 13C-pyruvate labelling. PloS one. 13, e0204398 (2018), doi:10.1371/journal.pone.0204398.

54. J. de Gouw et al., Sensitivity and specificity of atmospheric trace gas detection by proton-transfer-reaction mass spectrometry. International Journal of Mass Spectrometry. 223-224, 365-382 (2003), doi:10.1016/S13873806(02)00926-0.

55. R. Holzinger, PTRwid: A new widget tool for processing PTR-TOF-MS data. Atmospheric Measurement Techniques. 8, 3903-3922 (2015), doi:10.5194/amt-8-3903-2015.

56. J. de Gouw, C. Warneke, Measurements of volatile organic compounds in the earth's atmosphere using protontransfer-reaction mass spectrometry. Mass spectrometry reviews. 26, 223-257 (2007), doi:10.1002/mas.20119.

57. R. Holzinger et al., Validity and limitations of simple reaction kinetics to calculate concentrations of organic compounds from ion counts in PTR-MS. Atmos. Meas. Tech. 12, 6193-6208 (2019), doi:10.5194/amt-12-61932019.

58. J. M. Zobitz, J. P. Keener, H. Schnyder, D. R. Bowling, Sensitivity analysis and quantification of uncertainty for isotopic mixing relationships in carbon cycle research. Agricultural and Forest Meteorology. 136, 56-75 (2006), doi:10.1016/j.agrformet.2006.01.003.

59. Pinheiro J, Bates D, DebRoy S, Sakar D, R Core Team, nlme: Linear and Nonlinear Mixed Effects Models. R package version 3.1-152 (2021).

60. S. Wood, Generalized Additive Models, An Introduction with R (CRC Press, Hoboken, 2006). 
372 Acknowledgments: We acknowledge valuable support from all members of the B2WALD team, 373 as detailed in the B2WALD contribution list (doi: 10.25422/azu.data.14632662). Funding: This work was funded by the European Research Council [ERC consolidator grant \#647008 (VOCO2) to C.W.] and financial support from the Philecology Foundation to Biosphere 2 to L.M, with inkind support detailed elsewhere (doi: 10.25422/azu.data.14632662). Author contributions: C.W., L.M., and N.L. conceived and designed the study; all authors collected and/or analyzed data; C.W. wrote the first draft with input from L.M. and N.L. Data analysis was led by J.I., A.K., J.vH., D.B., J.K., L.M., N.L., and C.W., with input from all authors. All authors revised the manuscript. Competing interests: Authors declare no competing interests. Data and materials availability: All data used in this manuscript is publicly available (DOI: 10.25422/azu.data.14632593).

\section{Figure Legends} and recovery. Daily means of (A) vapor pressure deficit (VPD) in the tree canopy and understory, and soil matric potential in shallow and deep soil, (B) ecosystem evapotranspiration and tree water loss, (C) ecosystem $\mathrm{CO}_{2}$ fluxes gross primary productivity (GPP), ecosystem respiration $\left(\mathrm{R}_{\mathrm{eco}}\right)$ and net ecosystem exchange (NEE), (D) drought phases, (E) atmospheric VOC concentrations (F) daily maximum soil uptake rate of isoprene and monoterpenes $(n=12)$, and $(\mathrm{G})$ daily means of 390 stem $(n=12)$ and soil respiration $(n=12)$. Background shadings in all panels match phases in (D).

391 The vertical dark gray line indicates deep soil rewetting. Thick lines are smoothing splines with $39295 \%$ confidence intervals. Thin lines in (A) - (C) are daily mean fluxes. 


\section{Fig. 2. Physiological responses of different plant functional groups and impact on total water}

flux. (A) Sap flow (SF; $n=3-8$ individuals per functional group), (B) normalized total water flux (normalized TWF) and relative functional group contribution (\%), (C) predawn (pLWP) and (D) midday (mLWP) leaf water potential $(n=3-6)$. Lines are based on locally estimated scatterplot smoothing. Background shading as in Fig. 1. For information on plant grouping see Table S1.

\section{Fig. 3. Deep-water uptake and recovery of plant functional groups. $\mathrm{A}{ }^{2} \mathrm{H}_{2} \mathrm{O}$-pulse was} applied at depth on day 336 (gray line) 10 days before rain. (A) $\delta^{2} \mathrm{H}_{\mathrm{t}}$ of leaf transpiration (\%o) (n = 5-10 per functional group), (B) tree water content (TWC; $n=2-6$; full time series shown in Fig. S6), (C) soil water content per depth (\% vol.), and (D) rain events after drought. Lines in A$\mathrm{C}$ are based on locally estimated scatterplot smoothing. No data were available for TWC of drought tolerant understory. For information on plant grouping see Table S1.

\section{Fig. 4. ${ }^{13} \mathrm{C}$-dynamics in fluxes and pools of ecosystem compartments following pulse labeling.} Isotopic composition in (A) atmospheric $\mathrm{CO}_{2},(\mathrm{~B}, \mathrm{C})$ leaf respiration $(\mathrm{n}=3-6$ per functional group), (D) stem respiration $(\mathrm{n}=3-6)$, (E) soil $\mathrm{CO}_{2}$-efflux $(\mathrm{n}=12)$, atmospheric $(\mathrm{F})$ isoprene and (G) monoterpenes; relative to the time of ${ }^{13} \mathrm{CO}_{2}$-pulse labeling (grey shading) during pre-drought (blue) and drought (orange) conditions. (H) Uptake rate (left-axis) and cumulative uptake (rightaxis) of ${ }^{13} \mathrm{CO}_{2}$ during and in the initial hours after each labeling pulse, derived from ecosystem GPP and atmospheric $\delta^{13} \mathrm{CO}_{2}$. (I) Mean residence times of ${ }^{13} \mathrm{C}$ in leaf and stem-respired $\mathrm{CO}_{2}(\mathrm{n}=$ 3-6). Open and closed symbols in B-D denote drought-tolerant and -sensitive functional groups, respectively. Circles and triangles indicate canopy and understory, respectively. $\Delta$ Ratio in $(F, G)$ is the ${ }^{13} \mathrm{C}$-enrichment above the natural abundance of ${ }^{13} \mathrm{C}$-isotopologues. Insets in (A): strength of 
417 atmospheric $\delta^{13} \mathrm{CO}_{2}$ pulse; (D) and (F) $\delta^{13} \mathrm{C}$ of leaf and root samples $(\mathrm{n}=2-7)$, respectively.

418 Symbols show mean values $+/$ - standard error.

\section{SUPPLEMENTARY MATERIALS}

$421 \quad$ Materials and Methods

$422 \quad$ Figs. S1 to S9

S1: Illustration of rainforest mesocosm

S2: Plant map and 3D zones

S3: Rainforest sampling zones (2D profile)

S4: Timeline of the experiment - overview

$$
\text { S5: Monoterpene:Isoprene deposition velocity ratio }
$$

S6: Tree water content

S7: Key fluxes during drought and recovery

S8: Correlation matrices for ecosystem fluxes and environmental variables

S9: Gas sampling system

S1: Plant individuals and characteristics that were used when assigning functional groups

S2: Linear mixed effect model results for leaf assimilation, leaf respiration, and bulk leaf $\delta^{13} \mathrm{C}$ values

S3: General additive model results for respired ${ }^{13} \mathrm{C}$

S4: Linear mixed effect model results for ${ }^{13} \mathrm{C}$ residence times

S5: Temperature ranges, VPD, PAR at different phases of experiment

442

443 References (36-60)

444 
Figure 1
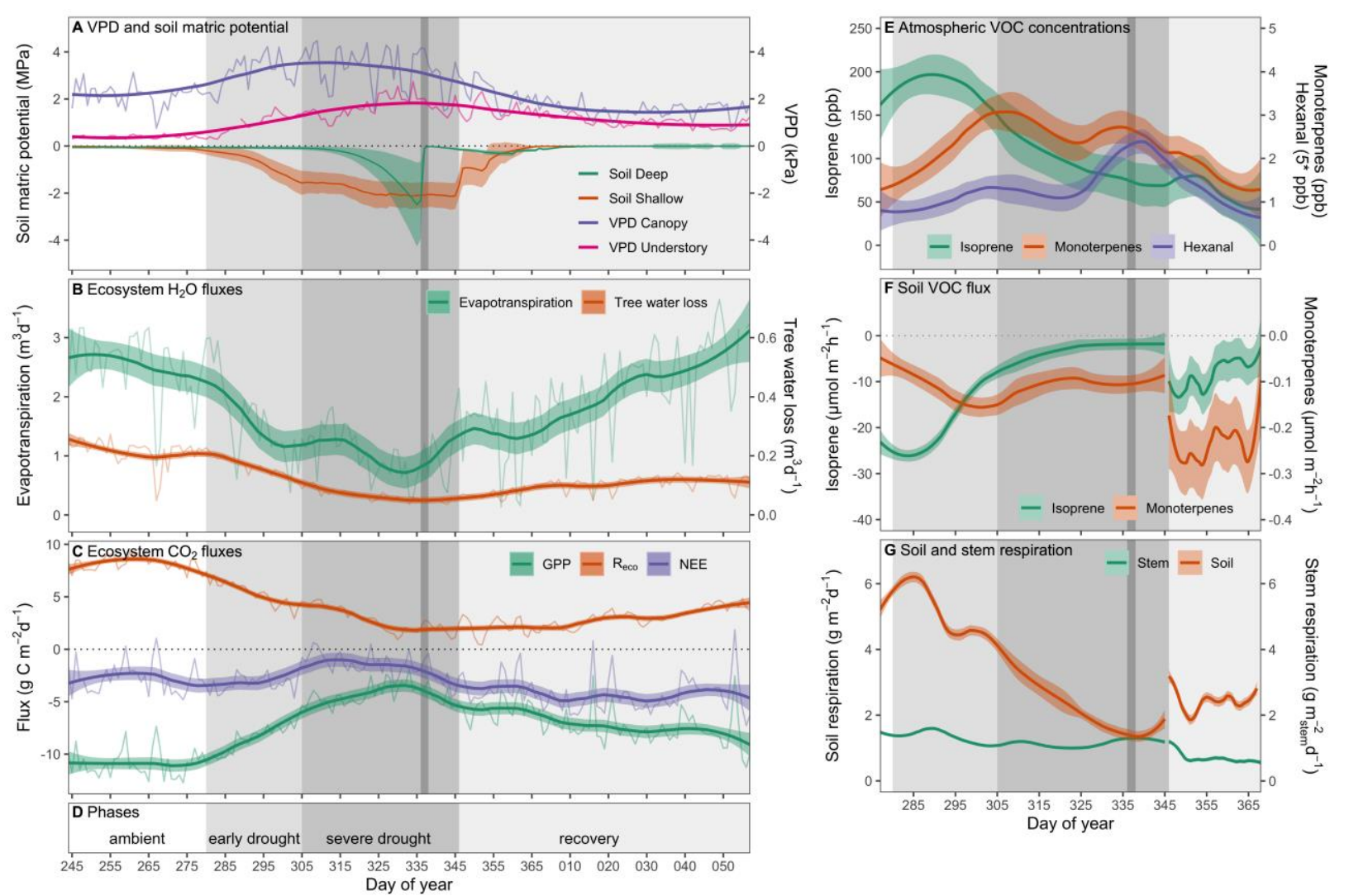
Figure 2
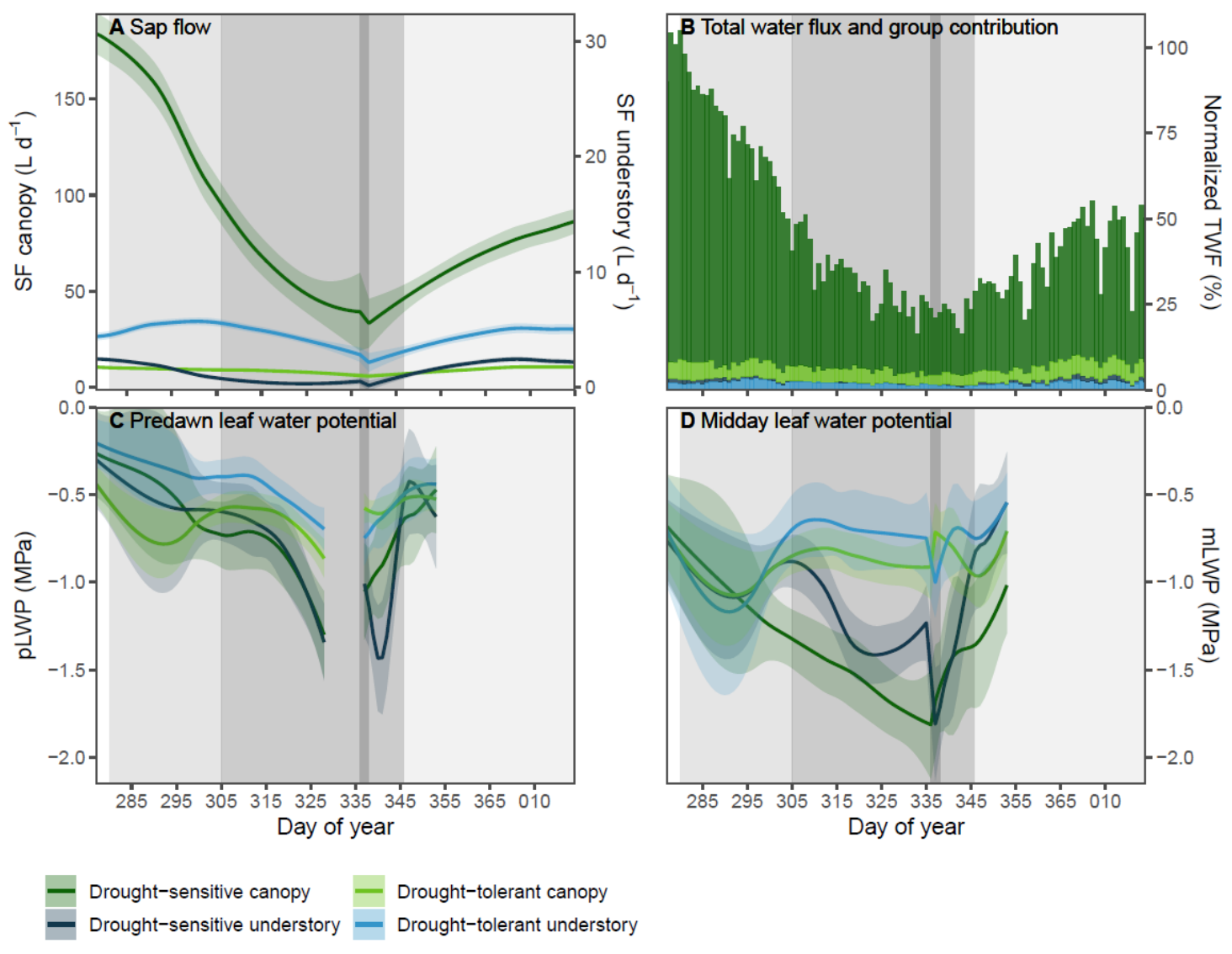

449

450 
Figure 3
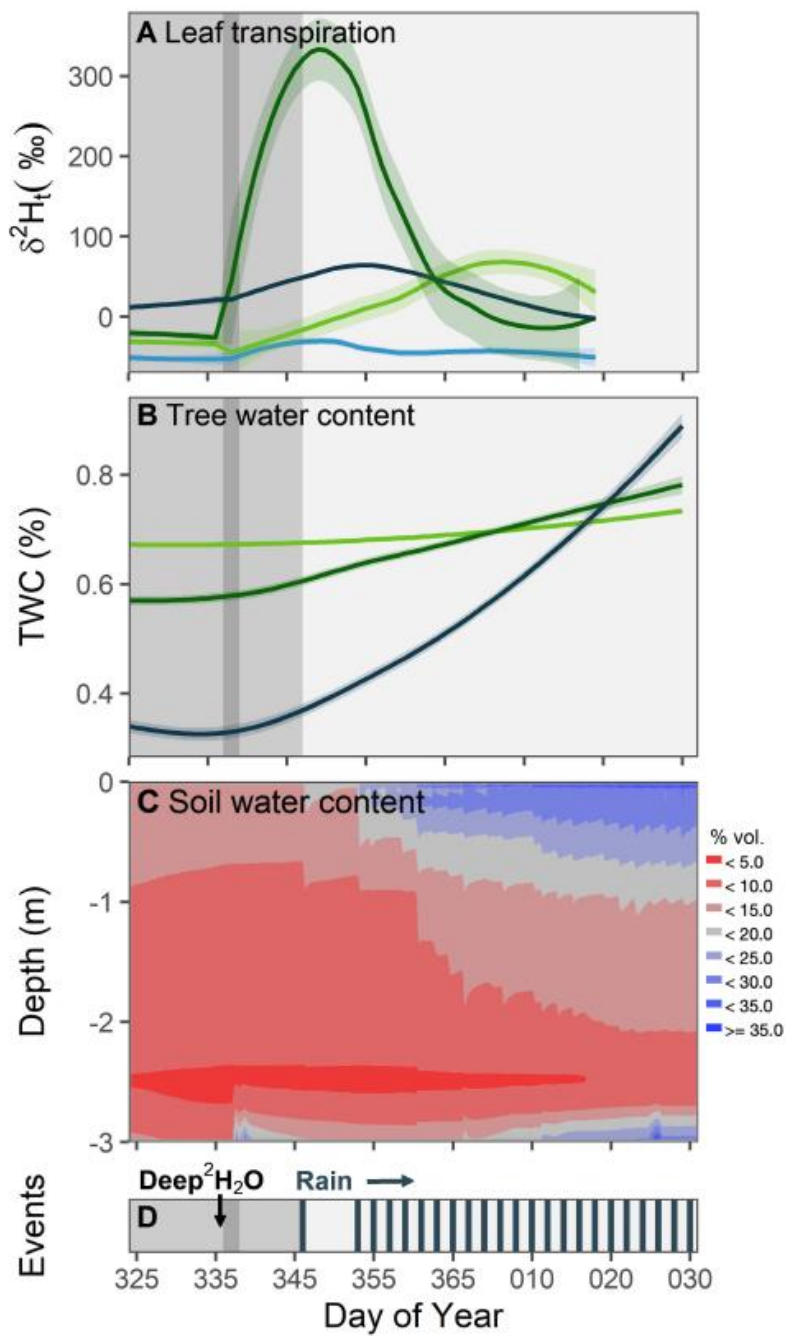

- Drought-sensitive canopy - Drought-tolerant canopy
452 - Drought-sensitive understory - Drought-tolerant understory 
Figure 4
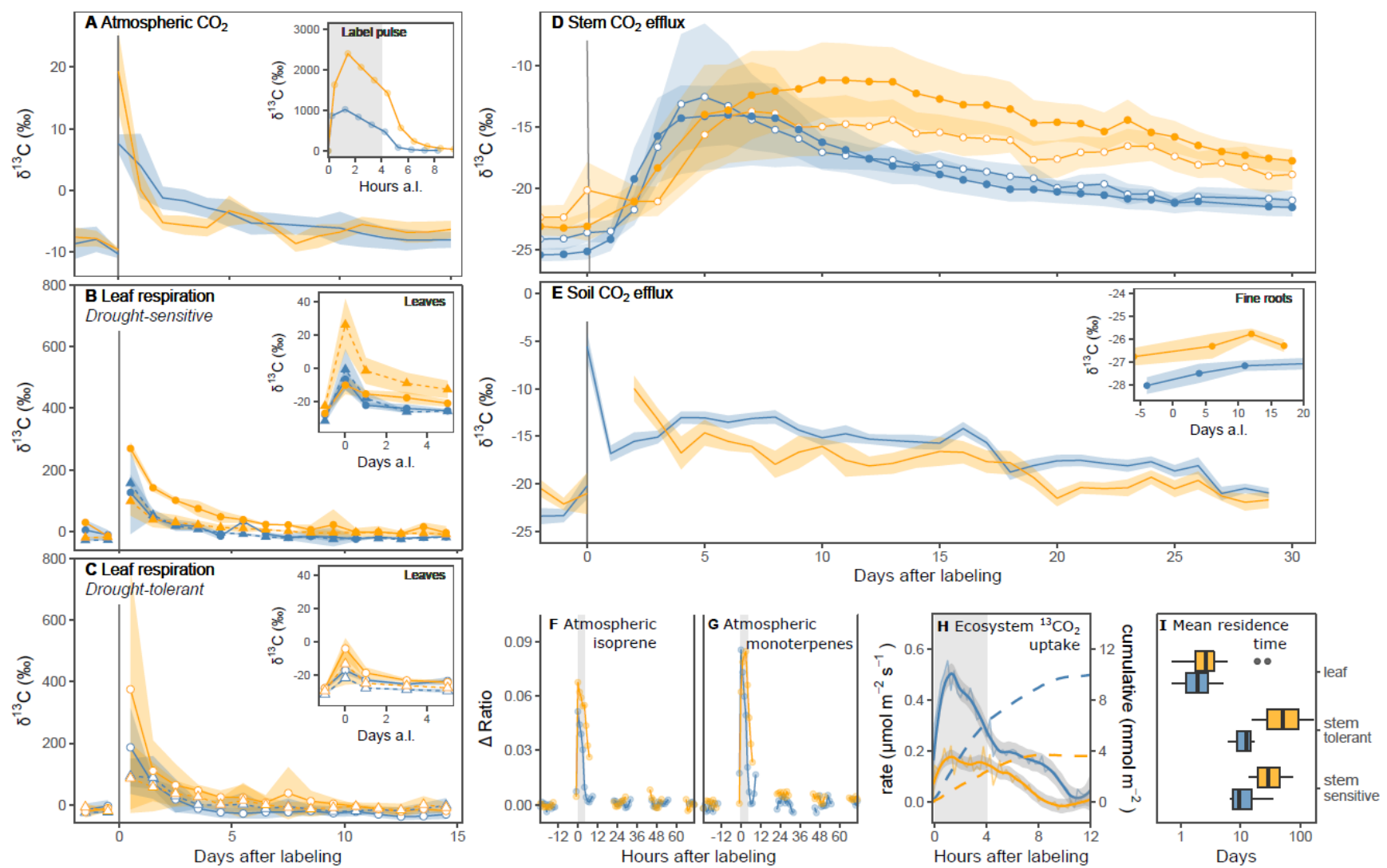

455

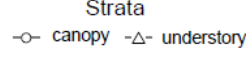

Campaign

Strategy

- sensitive otolerant 


\section{Science MIAAAS}

458

459

460

461

462

463

464

465

466

467

468

469

470

471

472

473

474

475

476

477

478

479

480

481

482

483

484

485

486

487

488

489

490

491

492

493

494

495

496

497

498

499

500

501

502

\section{Supplementary Materials for}

\section{Ecosystem fluxes during drought and recovery in an experimental forest}

Authors: Christiane Werner ${ }^{1 \dagger^{*}}$, Laura K. Meredith ${ }^{2,3 \dagger}$, S. Nemiah Ladd $^{1 \dagger}$, Johannes Ingrisch ${ }^{1,4}$, Angelika Kübert ${ }^{1}$, Joost van Haren ${ }^{3,5}$, Michael Bahn ${ }^{4}$, Kinzie Bailey ${ }^{2}$, Ines Bamberger ${ }^{1, \# 1}$, Matthias Beyer ${ }^{6}$, Daniel Blomdahl ${ }^{7}$, Joseph Byron $^{8}$, Erik Daber ${ }^{1}$, Jason Deleeuw ${ }^{3}$, Michaela Dippold ${ }^{9,10}$, Jane Fudyma ${ }^{11, \# 2}$, Juliana Gil-Loaiza ${ }^{2}$, Linnea K. Honeker $^{3}$, Jia $\mathrm{Hu}^{2}$, Jianbei Huang ${ }^{12}$, Thomas Klüpfel ${ }^{8}$, Jordan $\mathrm{Krechmer}^{13}$, Jürgen Kreuzwieser ${ }^{1}$, Kathrin Kühnhammer ${ }^{1,6}$, Marco M. Lehmann ${ }^{14}$, Kathiravan Meeran ${ }^{4}$, Pawel K. Misztal ${ }^{7}$, Wei-Ren $\mathrm{Ng}^{3}$, Eva Pfannerstill ${ }^{8, \# 3}$, Giovanni Pugliese $^{1,8}$, Gemma Purser ${ }^{15}$, Joseph Roscioli ${ }^{12}$, Lingling Shi ${ }^{9}, 10$, Malak Tfaily ${ }^{111617}$, Jonathan Williams ${ }^{8,18}$

\section{*Correspondence to: $\underline{\text { c.werner@ cep.uni-freiburg.de }}$ \\ †equal contributions}

\section{This PDF file includes:}

Materials and Methods

Figs. S1 to S9

S1: Illustration of rainforest mesocosm

S2: Plant map and 3D zones

S3: Rainforest sampling zones (2D profile)

S4: Timeline of the experiment - overview

S5: Monoterpene:Isoprene deposition velocity ratio

S6: Tree water content

S7: Key fluxes during drought and recovery

S8: Correlation matrices for ecosystem fluxes and environmental variables

S9: Gas sampling system

Tables S1 to S8

S1: Plant individuals and characteristics that were used when assigning functional groups

S2: Linear mixed effect model results for leaf assimilation, leaf respiration, and bulk leaf $\delta^{13} \mathrm{C}$ values

S3: General additive model results for respired ${ }^{13} \mathrm{C}$

S4: Linear mixed effect model results for ${ }^{13} \mathrm{C}$ residence times

S5: Temperature ranges, VPD, PAR at different phases of experiment

S6: Overview on plant analyses

S7: Instruments streams and analyzers on each stream

S8: VOC calibration standard composition 
503

504

505

506

507

508

509

510

511

512

513

514

515

516

517

518

519

520

521

522

523

524

525

526

527

528

529

530

531

532

533

534

535

536

537

538

539

540

541

542

543

544

545

546

547

548

549

550

551

552

553

554

555

556

557

558

\section{Materials and Methods}

Tropical Rainforest Mesocosm

The Biosphere 2 (B2) Tropical Rainforest (TRF) is a large-scale $\left(27,700 \mathrm{~m}^{3} / 1940 \mathrm{~m}^{2}\right.$ ) fully enclosed (glass-steelconcrete) mesocosm (Fig. S1-S3) near Tucson, AZ, USA containing a phylogenetically diverse assemblage of pantropical plant species $(36,37)$ with established $(30$-year old) interactions among the model ecosystem's pedosphere, hydrosphere, and atmosphere. The mesocosm is uniquely suited for controlled ecosystem-scale experiments that manipulate climate and atmospheric composition, precisely introduce tracers including stable isotope labeling, and capture processes across plot to ecosystem scales $(20,38)$. The tropical rainforest is particularly well-suited for drought and rewet experiments $(20,39-42)$ because climate and hydrological inputs (rain, groundwater) are directly controlled. The structural features of the system allow unparalleled access to ecosystem components for monitoring and sampling (e.g., soil subsurface, ecosystem drainage, canopy access). Due to these features, the mesocosm can be seen as a largescale cuvette to quantify net ecosystem exchange of energy and biogeochemical variables.

The forest is distributed across a topographically rich landscape rooted in 2-4 m of soil (sandy clay loam: 20-35\% clay and $>70 \%$ sand) underlain by an impervious concrete and steel floor with a piped drainage system $(37,43)$. Climate conditions are controlled to broadly reflect Earth's tropical rainforests. Overhead sprinklers deliver precipitation without strong seasonality. The precipitation regime is three times a week for approximately 1600 $\mathrm{mm} /$ year, unless drought experiments are conducted (41). TRF temperatures $\left(\sim 32{ }^{\circ} \mathrm{C}\right.$ on average) are warmer than Earth's tropical rainforests and vary seasonally with solar radiation in southern Arizona. Further, the glass enclosure establishes a stronger temperature inversion and lower VPD (under non-drought conditions) relative to external sites. Incoming solar radiation is reduced by approximately $40 \%$, and no radiation wavelengths below $385 \mathrm{~nm}$ pass through the mylar sheet in the glass panels (44). Due to this UV-screening glass, atmospheric oxidation effects are negligible and atmospheric VOC concentrations reflect the interplay between vegetation emissions and net exchange rates with soil (Fig. 1E, F). Overall, the well-developed TRF model ecosystem demonstrates broadly similar behavior to the world's tropical rainforests (20). It serves as a valuable model system to rigorously evaluate tropical ecosystem responses to warmer and hydrologically more variable climates.

We selected most dominant canopy forming tree species in the rainforest representing approximately $70 \%$ crown coverage. In particular, we choose all dominant species with sufficient replicates $(\mathrm{n}=4-5$, Clitoria fairchildiana $\mathrm{R}$. A. Howard - CF, Pachira aquatica Aubl.- PA, Phytolacca dioica L.- PD), beside three palm trees. Further we also included large individuals that contributed a significant part of the canopy (Ceiba pentandra (L.) Geartn- CP, Hibiscus tilliaceus L.- HT, Hura crepitans L.- HC), representing approximately $10 \%$ crown cover. For the understory, we selected representative species regarding their abundance and total cover (ca. $50 \%$, for species list see Table S1).

\section{Controlled Ecosystem Drought}

The B2-WALD campaign started in September 2019 with a pre-drought phase, followed by early drought, severe drought, and recovery periods (Fig. S4). The ecosystem was generally maintained within a temperature range between 21 and $37^{\circ} \mathrm{C}$ (day) and 20 and $27{ }^{\circ} \mathrm{C}$ (night) (Table S5) using air handling units (AHUs) and ventilation as needed. Ecosystem water content was manipulated with moisture addition (rain sprinklers or deep water) and removal (condensation and ventilation).

Ecosystem moisture manipulation began with turning off aesthetic water features (waterfall, stream, pond) before the experiment (31 May 2019) to ensure timely drought progress during the campaign. The forest was monitored for 36 days under pre-drought conditions with a rainfall regime of $\sim 30 \mathrm{~mm}$ per week or $\sim 1,600 \mathrm{~mm}$ per year. The early drought started on 8 October 2019 following the final rain (midnight 7 October 2019). During the severe drought (1 November 2019 to 2 December 2019), relative humidity was actively reduced using a large AHU, which first cooled the air leading to condensation, and then re-heated it to maintain temperature. During this period, a persistent water table in the isolated drainage basin of the Varzea sub habitat (Fig. S2) was manually drained to enhance drought conditions (12 November 2019). Water was not added to the system for 55 days (8 October 2019 to 2 December 2019) and the ecosystem went 65 days (8 October 2019 to 12 December 2019) without rain (Fig. S4). These moisture manipulations represented the second most extreme drought imposed on the B2 tropical rain forest. Of the eight prior droughts, only the one in 2014 (41) was more severe.

The forest was first rewet from below by adding a total amount of $\sim 23,000 \mathrm{~L}$ of ${ }^{2} \mathrm{H}$-labeled water to the subsurface drainage network over a four-day period spanning 2 to 5 December 2019 (see Ecosystem-Scale Isotope Labeling). The ecosystem response to the addition of water at the base of the ecosystem was monitored for 10 days, during which surface conditions continued to reflect severe drought. The end of the drought period was initiated with 
a rainfall event at 11:00 on 12 December $2019(\sim 35,000 \mathrm{~L}$ or $\sim 18 \mathrm{~mm})$. The second rainfall was conducted one week later (11:00 on 19 December, $36,000 \mathrm{~L}$ or $\sim 19 \mathrm{~mm}$ ) and subsequent rain events occurred every second day beginning at 00:00 on 21 December. In all subsequent rain events, $\sim 10 \mathrm{~mm}(20,000 \mathrm{~L})$ of water was added to the system over a 4.5-hour period. Rainfall was added on a quadrant-by-quadrant basis in 15-min periods.

\section{Ecosystem-Scale Isotope Labeling}

Stable isotope labeling was performed at a whole-ecosystem scale at three time points during the B2-WALD campaign: (1) atmosphere ${ }^{13} \mathrm{CO}_{2}$ labeling during pre-drought, (2) atmosphere ${ }^{13} \mathrm{CO}_{2}$ labeling during severe drought and (3) deep-water ${ }^{2} \mathrm{H}$ labeling in the latest part of the severe drought (Fig. S4).

99 atom $\%{ }^{13} \mathrm{CO}_{2}$ from gas tanks (Sigma Aldrich, St. Louis MO, USA) was released into the atmosphere at two ground-based locations at 8:00 on 5 October 2019 (pre-drought: $150 \mathrm{~L}$, maximum $\delta^{13} \mathrm{C}$ value at $20 \mathrm{~m}=+1183 \pm 4 \%$, Vienna Pee Dee Belemnite (VPDB)) and at 9:00 on 22 November 2019 (severe drought: $300 \mathrm{~L}$, maximum $\delta^{13} \mathrm{C}$ value at $20 \mathrm{~m}=+2541 \pm 222 \%$, VPDB), where the reported standard deviations (of 2-min averages) reflect rapid changes in atmospheric $\delta^{13} \mathrm{C}$ values during pulse labeling, especially during the second, stronger labeling. The ${ }^{13} \mathrm{CO}_{2}$ was rapidly mixed throughout the ecosystem by the fans and was widely distributed within $\sim 20$ minutes. The atmosphere remained sealed for 4.0 and 5.2 hours during the first and second labeling periods, respectively. To return to background $\delta^{13} \mathrm{C}$ values of atmospheric $\mathrm{CO}_{2}$ after labeling, the ecosystem was flushed by reinstating outside air ventilation and opening the windows of the rainforest for 4.3 and 5.2 hours following the first and second labeling periods, respectively. The longer and stronger labeling during drought was designed to ensure a similar ecosystem ${ }^{13} \mathrm{C}$ uptake as in pre-drought, even though assimilation rates were lower under drought (Fig. 1). A correspondingly longer ventilation period was required to flush the stronger label following this second labeling event.

Simultaneous to the pulse labeling, a second $\mathrm{CO}_{2}$ line was added to the gas-mixing manifold to deliver ${ }^{13} \mathrm{C}$ labeled $\mathrm{CO}_{2}$ (10 atom $\%{ }^{13} \mathrm{C}$, P/N 600180, MilliporeSigma, Burlington MA, USA) to leaf chambers (see Leaf measurements) to match the atmospheric ${ }^{13} \mathrm{CO}_{2}$ enrichment. The amount of $\mathrm{CO}_{2}$ added from the normal $5 \% \mathrm{CO}_{2} \operatorname{tank}$ source was meanwhile reduced to maintain typical leaf chamber total $\mathrm{CO}_{2}$ concentrations (for further details of the gas sampling system, see Composition and Gas Exchange of Ecosystem Compartments).

Deep water enriched in ${ }^{2} \mathrm{H}$ was added in the final phase of severe drought (see Controlled Ecosystem Drought). $14,000 \mathrm{~L}\left(\delta^{2} \mathrm{H} \sim 3000 \%\right.$, Vienna Standard Mean Ocean Water (VSMOW)) were pumped into the soil via the subsurface drainage network (along the steel/concrete base of the enclosed system) and an additional 9,000 L ( $\delta^{2} \mathrm{H} \sim$ $1500 \%$, VSMOW) were added at the bottom of vertical 6" PVC pipes and soil pits to the base of the ecosystem to ensure an even distribution of ${ }^{2} \mathrm{H}$-labeled deep water.

\section{Destructive sampling}

Throughout the campaign leaf and root material was sampled to monitor leaf water potential (LWP) and to track carbon allocation through the system.

\section{Leaf water potential}

A total of nine plant species were monitored for leaf water potential, with six of the species having multiple replicates (see Table S1, S6 for species selection and grouping). Care was taken to select 1) proper leaf dimension for leaf water potential to be accurately determined using a Scholander type pressure chamber (PMS Instrument Company, OR, USA) (45), 2) spatial location within the rainforest biome, and 3) compatibility with other data collection goals of the B2-WALD campaign.

Predawn (pLWP) and midday water potential (mLWP) measurements were conducted throughout the experiment, with both $\mathrm{pLWP}$ and $\mathrm{mLWP}$ measured during the dry-down/drought phase (25 October 2019, 1 November 2019, 8 November 2019, 15 November 2019, 24 November 2019), deep re-wet (3 December 2019, 6 December 2019), and recovery (13 December 2019, 20 December 2019). Additional pLWP measurements were conducted on 1 October 2019 and additional mLWP were conducted on 23 August 2019, 25 September 2019, and 1 December 2019. To adjust for later sunrise, pLWP was measured at 05:30 in August and at 06:30 by December. mLWP measurements were made from 10:00 to 11:00, since previous studies from the tropical forest biome have found that plant activity decreases after 11:00, when temperatures increase in the biome (20). Late morning mLWP measurements allowed us to sample leaves at the most negative water potential values. For both predawn and midday WP measurements, all leaves were collected within 30 minutes by climbers ascending into the rainforest canopy. Typically, large branches were collected in the canopy from which small twigs with 3-5 leaves were measured. In instances when whole branches were not collected, cut leaves were placed into ziplock bags and sealed until measurement (within 5 minutes). 
615

616

617

618

619

620

621

622

623

624

625

626

627

628

629

630

631

632

633

634

635

636

637

638

639

640

641

642

643

644

645

646

647

648

649

650

651

652

653

654

655

656

657

658

659

660

661

662

663

664

665

666

667

668

669

\section{Leaf sampling}

To track assimilation of $\mathrm{C}$ into leaf tissue during the pre-drought and drought period we collected fresh leaf matter from representative species (Table S6). We collected leaves within the week before each ${ }^{13} \mathrm{CO}_{2}$-pulse and then $0,1,3$, and 5 days after the labeling. On each sampling day, we collected leaves during a 30-minute window in the late morning, when assimilation in the TRF is highest (20). Leaves were transferred to $50 \mathrm{~mL}$ plastic tubes and immediately frozen in liquid nitrogen or dry ice to stop metabolic activity. All leaf samples were stored at $-20^{\circ} \mathrm{C}$ until further processing.

\section{Leaf $\delta^{13}$ C analysis}

Leaf samples were freeze-dried at the University of Arizona and sent to the Max Planck Institute for Biogeochemistry (Jena, Germany) for isotopic analysis. Samples were ground to fine powder using a ball mill (Retsch ${ }^{\circledR}$ MM400, Haan, Germany). Approximately $0.1 \mathrm{mg}$ of ground material was weighed into tin cups and analyzed with a Finnigan Delta Plus XL EA-IRMS (Thermo Finnigan GmbH, Bremen, Germany) coupled to an autosampler. For every 20-25 samples, approximately 5-7 standards (acetanilide, $-30.06 \%$ ) were measured to reference the samples to the VPDB scale with a single point calibration. The precision of the $\delta^{13} \mathrm{C}$ measurements of the acetanilide standard was $<0.16 \%(1 \sigma)$. Caffeine $(-40.46 \%$ ) was also measured as a quality control after every 25 samples, and was always within $0.2 \%$ of its known value.

\section{Root sampling}

To collect fine root samples, soil cores were collected at six representative locations throughout the rainforest ecosystem (Fig. S2b; near all four pit locations P1-4 and two additional root sampling sites). Of those sampling locations, four sites (Sites 1-4) were paired with the automatic soil chamber locations, all of which were adjacent to tall tree species (see Composition and gas exchange of ecosystem compartments, Soil fluxes). The additional sampling sites (Sites 5 and 7) were in locations dominated by understory plants. Cores were collected seven times between 1 October 2019 and 11 December 2019 from four randomized positions within each of the six sites. The seven sampling dates included one pre-label sampling (1 October 2019) and three sampling points within 30 days following each of the two ${ }^{13} \mathrm{CO}_{2}$ pulses.

Cores were collected with a manual root auger $(8 \mathrm{~cm}$ diameter), immediately separated into three depth increments $\left(0-15 \mathrm{~cm}, 15-30 \mathrm{~cm}\right.$ and 30-50 cm), transferred into clean plastic bags and cooled to $4{ }^{\circ} \mathrm{C}$. Within three days, fine roots were carefully removed from each sample manually with tweezers.

\section{Root processing and $\delta^{13} \mathrm{C}$ analysis}

Fine root biomass was freeze-dried in paper bags, dry weight per soil increment was measured, and the biomass was finely ground in a ball mill. Approximately $0.5-1 \mathrm{mg}$ of root material was weighed into tin capsules to prior to measuring $\delta^{13} \mathrm{C}$ values with a Costech ECS 4010 elemental analyzer (CostechAnalytical Technologies Inc. Valencia, USA) coupled by a ConFlo III interface to a Delta C IRMS (both units from Thermo Fisher Scientific, Bremen, Germany) at the Center of Stable Isotope analysis (KOSI, Goettingen, Germany). For every 8 samples, 2 standards (acetanilide, $-29.73 \%$ ) were measured to reference $\delta^{13} \mathrm{C}$ measurements to the VPDB scale with a single point calibration. The precision of the acetanilide standard was $<0.05 \%$ o $(1 \sigma)$.

\section{Environmental sensors}

Environmental conditions in the B2 TRF were monitored along four above and below ground sensor profiles (Fig. S2, S3). The four profile locations were chosen to represent the complete vertical gradient and main forest areas.

\section{Above ground sensor profiles}

Sensors were located at 1, 3, 7, 13, and (only $\mathrm{S}$ and NE towers) $20 \mathrm{~m}$ height above the soil surface (Fig. S3). At each level we measured photosynthetic active radiation (PAR) (Apogee SQ110, Campbell Scientific, Logan, UT, USA), temperature, and relative humidity with Vaisala HMP 45c sensors (Vaisala Oyi., Vantaa, Finland), housed in a naturally-aspirated solar radiation shield (Campbell Scientific 41003-5, Logan, UT, USA). All sensors were recalibrated in Spring 2019 either by factory calibration (light and wind sensors and some temperature/humidity sensors) or cross-calibrated to factory-calibrated sensors.

From the temperature (T) and relative humidity (RH), we calculated the vapor pressure deficit (VPD in $\mathrm{kPa}$ ) based on the saturated vapor pressure equation:

$$
V P D=0.6108\left(1-\frac{R H}{100}\right) e^{\frac{17.27 T}{(237.3+T)}}
$$


670

671

672

673

674

675

676

677

678

679

680

681

682

683

684

685

686

687

688

689

690

691

692

693

694

695

696

697

698

699

700

701

702

703

704

705

706

707

708

709

710

711

712

713

714

715

716

717

718

719

720

721

722

723

724
VPD values were averaged per height zone (H1-5) as shown in Fig. S3. Zones H1 and H2 were considered representative of the understory, while Zone H4 was considered representative of the canopy conditions (as median height of the canopy).

We measured the $\mathrm{CO}_{2}$ concentration in three different heights $(1,13$, and $27 \mathrm{~m}$ above the soil surface, Fig. S3) using Vaisala GMP 343 sensors (Vaisala Oyi., Vantaa, Finland). The sensors reported the one-minute averaged $\mathrm{CO}_{2}$ concentration every 15 minutes. Prior to mounting, the $\mathrm{CO}_{2}$ sensors were calibrated to four $\mathrm{NOAA} \mathrm{CO}_{2}$ standard tanks (ranging from 300 to $500 \mathrm{ppm} \mathrm{CO}$ ). For carbon budget calculations, we divided the rainforest profile into three height zones (C1-3, see Fig. S3)

Air pressure was measured with two WeatherHawk 520 stations (Vaisala Oyi., Vantaa, Finland) in a central location in the rainforest ( $2 \mathrm{~m}$ height along the NE tower, from the start of the experiment until 31 October 2019) and across one of the AHUs in the basement (AHU\#1 from 31 October 2019 until the end of the experiment). We placed the WeatherHawks in the central part of the AHU inlet and outlet to measure wind speed, direction, air pressure, humidity and temperature. The units were cross-calibrated before installation across the AHU (at $\sim 1.5 \mathrm{~m}$ height on the NE tower). WeatherHawk data were reported at one-minute intervals on a CR1000x using an SDI-12 protocol.

\section{Below ground sensor profiles}

Four soil pits $(0.9 \times 1.5 \mathrm{~m})$ spanning the vertical distance from soil surface to the concrete sub-surface underlying the soil (bottom depths: P1 = $180 \mathrm{~cm}, \mathrm{P} 2=310 \mathrm{~cm}, \mathrm{P} 3=290 \mathrm{~cm}, \mathrm{P} 4=200 \mathrm{~cm}$ ) were installed $(\mathrm{P} 1$, P3, and P4 in 2010 and 2011; P2 in Summer 2019) at different locations across the rainforest ecosystem (Fig. S2). Aluminum casing and plexiglass windows were used to stabilize soil pit walls. The soil was accessible via holes within the plexiglass (10 $\mathrm{cm}$ diameter), which were used to install and maintain sensors throughout the experiment. Only sensors in $5 \mathrm{~cm}$ soil depth were installed from the soil surface. In July 2019, soil moisture and temperature sensors (output VWC $\mathrm{m}^{3} \mathrm{~m}^{-3}$ and $\mathrm{T}^{\circ} \mathrm{C}$ SMT100, Truebner Gmbh, Neustadt, Germany) and soil water potential sensors (output WP $\mathrm{kPa}$ and $\mathrm{T}{ }^{\circ} \mathrm{C}$ TEROS 21, Meter Group, Pullman, WA, USA) were installed in all four pits at 5, 10, and $20 \mathrm{~cm}$ depth. The SMT100 sensors were also installed at 50,100, $200 \mathrm{~cm}$ (for pits deeper than $2 \mathrm{~m}$ ), and right above the surface of the concrete.

Soil water potential (WP) for the shallow soil was calculated based on the average of the 5 and $10 \mathrm{~cm}$ TEROS 21 probes from all four pits. The deep soil WP was calculated based on the soil moisture measurements at the bottom of each soil pit and the water retention curve for gravel-soil mixtures. Gravel content and soil parameters were based on soil texture analysis from at least three samples per pit.

\section{Tree stem moisture content measurements}

To continuously measure the water content and subsequently quantify the total amount of water stored in tree xylem, we inserted a total of 11 time-domain reflectometers $(10$ and $15 \mathrm{~cm}$ needle length; TDR, 310H and $315 \mathrm{H}$, Acclima Inc., Meridian, ID, USA) at $\sim 1.3 \mathrm{~m}$ height into the stems of predominantly the upper canopy tree species (Table S6), but also two understory trees (PA2 and PA3). CF individuals commonly consisted of multiple stems. For $\mathrm{CF} 3$, sensors were installed in the two main stems (CF3a and CF3b). To install the probes, a drill-guide was strapped to the tree and $1 / 8$ " holes were carefully drilled into the stem. The probes were then lubricated with wood polish (Howard Feed-N-Wax, Howard Products Inc, Paso Robles, USA) and inserted into the stems. The TDR probe data output included the volumetric water content $\left(\mathrm{VWC} \mathrm{m}^{3} \mathrm{~m}^{-3}\right)$ and the housing temperature. The $315 \mathrm{H}$ sensors, featuring longer needles of $15 \mathrm{~cm}$ length, were installed in the trees with the largest DBH (CF3a, CP, HC, HT, PA4, and PD1) (Tables S1; S6).

\section{Sap flow measurements}

To quantify water transported in tree xylem, a total of 16 heat-pulse velocity sap flow sensors (HPV-06, Implexx Sense, Edaphic Scientific, Melbourne, Australia) were installed in individuals of seven different species (Table S6). The installation height was 110-130 cm above ground for all trees except HR, which were shrub individuals with multiple small stems. HR sensors were installed at 10-40 cm above ground. Both CF3 and CF4 were equipped with two sap flow sensors (CF3a,b and CF4a,b) to evaluate variability between their multiple stems. For individuals with a bark depth $>0.6 \mathrm{~cm}$, bark was removed to ensure the location of the outer measuring point within conductive sap wood. Similar to the TDR probes, a drilling guide was strapped to the tree trunk, holes were drilled, sensor needles were lubricated with wood polish and pushed inside predrilled holes. Finally, sensors were insulated on the outside to reduce the impact of air temperature variations on measurements.

We calculated tree sap flux density $\left(\mathrm{V}_{\mathrm{s}}\right.$ in $\left.\mathrm{cm} \mathrm{hr}^{-1}\right)$ from the raw sap flow sensor output according to (46): 


$$
V_{s}=\frac{V_{h}^{\prime} \rho_{b}\left(C_{w}+m C_{s}\right)}{\rho_{s} C_{s}}
$$

726

727

728

729

730

731

732

733

where $V_{h}$ ' is the measured sap flux velocity corrected for wounding and probe misalignment (zero offset), $\rho_{\mathrm{b}}$ and $\rho_{\mathrm{s}}$ are wood (Table S1) and sap $\left(1000 \mathrm{~kg} \mathrm{~m}^{-3}\right)$ density, respectively; $\mathrm{C}_{\mathrm{w}}$ and $\mathrm{C}_{\mathrm{s}}$ are the specific heat capacities of dry wood $\left(1200 \mathrm{Jg}^{-1}{ }^{\circ} \mathrm{C}^{-1}\right)$ and sap $\left(4182 \mathrm{~J} \mathrm{~g}^{-1}{ }^{\circ} \mathrm{C}^{-1}\right)$, respectively; and $m$ is the moisture content of sapwood (derived from the stem moisture measurements with the TDR probes). The whole tree sap flux $\left(\mathrm{Q}, \mathrm{L}, \mathrm{d}^{-1}\right)$ was then calculated based on the tree radius and $\mathrm{V}_{\mathrm{s}}$ for both the outer and inner measurement location (0.5-1.5 and 1.5-2.5 cm into the tree), the knowledge that sap fluxes decrease with depth in the tree (47-49), and that we observed no change from sapwood to heartwood in the cores from any of the trees we measured.

The calculations were based on the tree radius (to closest integer value not including bark (estimated to be $\sim 0.5 \mathrm{~cm}$ deduction)/sap-flowing radius and $\mathrm{V}_{\mathrm{s}}$ for both the inner and outer measurement location (47-49):

$$
Q=\frac{\left(\pi\left(\mathrm{r}^{2}-(r-1)^{2}\right) V_{s}^{o}+\pi\left((r-1)^{2}-(r-2)^{2}\right) V_{s}^{I}\right)+\sum_{i=2}^{i=r-1} \pi\left((r-i)^{2}-(r-i-1)^{2}\right) * \begin{array}{l}
\text { If } R V_{h}^{\prime}>1 \text { then } V_{s}^{I} \frac{1}{\left(R V_{h}^{\prime}\right)^{i}} \\
\text { If } R V_{h}^{\prime}<1 \text { then } V_{s}^{I}\left(R V_{h}^{\prime}\right)^{i}
\end{array}}{1000}
$$

where $\mathrm{r}$ stands for the stem radius and the numerical subtractions denote the reduction in radius based on a $1 \mathrm{~cm}$ measurement width for each of the thermistors. $\mathrm{V}_{\mathrm{s}}{ }^{O}$ and $\mathrm{V}_{\mathrm{s}}{ }_{\mathrm{s}}$ stand for the calculated outer and inner sap flux velocity and $\mathrm{RV}_{\mathrm{h}}$ for the ratio of the measured outer and inner sap velocity $\mathrm{V}_{\mathrm{h}}{ }^{O} / \mathrm{V}_{\mathrm{h}} \mathrm{I}$.

Finally, we summed the total tree water fluxes (TWF) from the individual measured stems for the total water flux changes shown in Fig. 1. Since the measured trees are only about one third of the total TRF tree population, we presume even the total $\mathrm{Q}$ water flux to be a severe underestimation of the total TRF water flux.

\section{Ecosystem Calculations \\ Exchange rate measurements}

Air exchange rates (ER) of the Biosphere 2 rainforest ecosystem with the outside air represent the biome's atmospheric residence time when (normally) operated in flow-through mode and the leak rate through the glass and steel enclosure when (infrequently) operated in closed mode. We measured ER with a conserved, purely man-made tracer (sulfur hexafluoride, $\mathrm{SF}_{6}$ ) 187 times during the experiment. For each measurement, 25 to $30 \mathrm{~mL} \mathrm{SF}_{6}$ were injected into the rainforest to generate a concentration of $\sim 1 \mathrm{ppb}(\sim 125$ times background air at $\sim 8 \mathrm{ppt})$. The $\mathrm{SF}_{6}$ was sampled next to the instrument laboratory with a single, filtered inlet connected to $1 / 4$ " OD Teflon tubing. $\mathrm{SF}_{6}$ concentration was measured on a SRI Greenhouse Gas GC (SRI Instruments, Torrance, CA, USA) with an automated sample loop of $1 \mathrm{ml}$ using an ECD detector at $350{ }^{\circ} \mathrm{C}$. $\mathrm{SF}_{6}$ in the sample and carrier UHP $\mathrm{N}_{2}$ stream was separated from $\mathrm{N}_{2} \mathrm{O}$ using a Hayesep D column at $65{ }^{\circ} \mathrm{C}$. Each sample was collected and analyzed every 2.5 minutes. The exchange rate was calculated for the exponential decay of the $\mathrm{SF}_{6}$ concentration in the Biosphere 2 rainforest and reported as \% per hour.

\section{Ecosystem Carbon Cycling}

Net Ecosystem Exchange (NEE) is the exchange of carbon dioxide $\left(\mathrm{CO}_{2}\right)$ between the atmosphere and ecosystems. In most forest ecosystem studies NEE is based on eddy covariance tower measurements. Sufficient turbulence in the enclosed Biosphere 2 rainforest is lacking, invalidating the eddy covariance method (50). Instead, we treated Biosphere 2 as a flow-through mesocosm and measured atmospheric concentration changes within the mesocosm, as well as the flow rate and concentration of the incoming outside air. NEE was calculated for every 15minute time step according to:

$$
N E E=\left(\mathrm{CO}_{2}^{t}-\mathrm{CO}_{2}^{t-1}\right)+\mathrm{CO}_{2}^{E R}
$$

where the first right-hand term is the change between 15-minute time steps in moles of $\mathrm{CO}_{2}$ inside Biosphere 2 rainforest, based on three measurement locations at different heights. $\mathrm{CO}_{2}{ }^{\mathrm{ER}}$ is the $\mathrm{CO}_{2}$ adjustment due to the exchange rate. The moles of $\mathrm{CO}_{2}$ in the rainforest were calculated according to: 


$$
C O_{2}=\sum \frac{V_{T R F} * F_{\text {Zone }} * P}{\left(273.15+T_{\text {Ave }}\right) * R} * \frac{\left[\mathrm{CO}_{2}\right]}{10^{6}}
$$

where $\mathrm{V}_{\mathrm{TRF}}$ is the rainforest volume $\left(27,700 \mathrm{~m}^{3} ;(19)\right), \mathrm{F}_{\text {Zone }}$ is the volume fraction of the height zone based on geometric calculations $(0.304,0.588$, and 0.108 , for Zone $\mathrm{C} 1, \mathrm{C} 2$, and $\mathrm{C} 3$ respectively), $\mathrm{P}$ is the air pressure, $\mathrm{R}$ the gas constant and $\left[\mathrm{CO}_{2}\right]$ the $\mathrm{CO}_{2}$ concentration.

The exchange rate (ER) $\mathrm{CO}_{2}$ adjustment was calculated based on:

$$
\mathrm{CO}_{2}^{E R}=\left(\frac{\left[\mathrm{CO}_{2}^{27 m}\right]}{10^{6}}-\frac{\left[\mathrm{CO}_{2}^{\text {Out }}\right]}{10^{6}}\right) * \frac{V_{T R F} * E R * P}{\left(273.15+T_{27 m}\right) * R}
$$

The outside air was measured once an hour in the inflow tube with a dual laser QCL (Aerodyne, Billerca, MA, USA). Gaps in the QCL record were filled with $\mathrm{CO}_{2}$ data from two nearby locations: 1) a well-ventilated space without plants in the Biosphere 2 (Landscape Evolution Observatory (51)) and 2) the Santa Rita Experimental Range NEON site.

From the NEE, we calculated ecosystem respiration $\left(R_{\text {eco }}\right)$ by taking the mean nighttime NEE per day, according to (21). Then gross primary production (GPP) was calculated from: GPP $=\mathrm{NEE}+\mathrm{R}_{\mathrm{eco}}$ and daily values were reported based on the sum of the GPP values.

\section{Evapotranspiration}

Whole ecosystem evapotranspiration (ET, the loss of water $\left(\mathrm{H}_{2} \mathrm{O}\right)$ from ecosystems to the atmosphere) was calculated based on the water balance from each 15-minute time step according to:

$$
E T=\frac{\Delta \mathrm{H}_{2} \mathrm{O}+\left(\mathrm{H}_{2} \mathrm{O}_{27 m}-\mathrm{H}_{2} \mathrm{O}_{\text {out }}\right) * E R * V_{T R F}+\Delta \mathrm{H}_{2} \mathrm{O}_{\text {AHU }}+\Delta \mathrm{H}_{2} \mathrm{O}_{\text {Dehumid }}+\Delta \mathrm{H}_{2} \mathrm{O}_{\text {Glass }}}{\text { Area }}
$$

where the first right-hand term is the change between 15-minute time steps in $\mathrm{kg}$ of $\mathrm{H}_{2} \mathrm{O}$ inside Biosphere 2 rainforest,

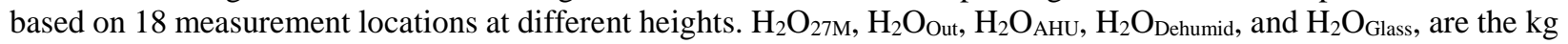
of $\mathrm{H}_{2} \mathrm{O}$ at the top of the rainforest, where the main air outflow louvers are, $\mathrm{H}_{2} \mathrm{O}$ in outside air, $\mathrm{H}_{2} \mathrm{O}$ removed during cooling with the $\mathrm{AHU}, \mathrm{H}_{2} \mathrm{O}$ removed when one $\mathrm{AHU}$ was used to dehumidify (first cool and then heat the air) the rainforest for the enhanced drought phase, and the maximum amount of water removed by condensation on the glass when the outside air temperature was much lower than the inside temperature. Hourly ET was divided by four for the 15-minute time steps. Area and $\mathrm{V}_{\mathrm{TRF}}$ denote the rainforest ground surface area and volume $\left(1940 \mathrm{~m}^{2}\right.$ and $26,700 \mathrm{~m}^{3}$; $(20))$.

The same HMP45C probes (Vaisala Oyi., Vantaa, Finland) used to calculate VPD were used to calculate the vapor density (VD, in $\mathrm{kg} \mathrm{m}^{-3}$ ) using the following equation (based on (52) and the ideal gas law):

$$
V D=\frac{0.002166 *\left(610.78 * e^{\frac{T}{(T+238.2)} * 17.2694}\right) *\left(\frac{R H}{100}\right)}{(T+273.15)}
$$

where $\mathrm{T}$ stands for temperature and $\mathrm{RH}$ the relative humidity measured at each location.

All temperature data were averaged over the five height zones (Fig. S3) as determined by the sensor locations for the final calculations. The mass of $\mathrm{H}_{2} \mathrm{O}(\mathrm{kg})$ in the rainforest air was calculated according to:

$$
H_{2} O=\sum_{x=1}^{5} V_{T R F} * F_{\text {Zone }} * V D_{\text {Zone }}
$$

where TRF stands for the whole rainforest and Zones $X=1$ through 5 are the different height zones outlined in Fig. $\mathrm{S} 3$, and $\mathrm{F}_{\mathrm{Z} \text { one }}$ is the volume fraction of the height zone based on geometric calculations $(0.176,0.360,0.243,0.135$ and 0.086 , for Zone 1 through 5 respectively).

Six AHUs were constantly used to control the temperature within the Biosphere 2 rainforest. During cooling phases, when the rainforest temperature was exceeding the target temperatures, the AHUs would also reduce the air water content through condensation. The amount of air removed by the AHUs during cooling was calculated based on: 


$$
H_{2} O=\sum_{x=1}^{A H U} v_{O u t} * A r e a_{A H U} *\left(V D_{A H U I n}-S a t V D_{A H U}\right) * e_{A H U}
$$

where vout is the air outflow velocity $(\mathrm{m} / \mathrm{s})$ of the AHU, Area $\mathrm{AHU}$ is the outflow area of the AHU, and VD AHUIn $_{\text {is the }}$ vapor density of the air coming into the AHUs based on the outside T, RH, and airflow (which enters the Biosphere 2 rainforest just before the AHU) and based on the remaining AHU outflow volume air and the T and RH at NW tower 1 and $3 \mathrm{~m}$ heights (closest to the return air intake), and $\mathrm{e}_{\mathrm{AHU}}$ is a water removal efficiency of the AHU based on the comparison of this method with the weather station (WeatherHawk) units placed at inflow and outflow points of different AHUs to test their efficiency.

The change in water across the dehumidifying AHU \#1 for each 15-minute time step was calculated based on:

$$
H_{2} O_{\text {Dehumid }}=v_{\text {out }} * \text { Area }_{A H U} *\left(V D_{\text {out }}-V D_{\text {In }}\right)
$$

where $\mathrm{VD}_{\text {In }}$ and $\mathrm{VD}_{\text {Out }}$ are the inflow and outflow vapor densities based on the T and RH of the WeatherHawk sensors in the inflow and outflow areas of the AHU.

During the winter months, outside air temperatures dropped well below inside air temperatures, causing the water vapor in the TRF to condense on the inside of the glass and steel space frame structure. The amount of water lost from the air through condensation on the glass space-frame $\left(\mathrm{H}_{2} \mathrm{O}_{\text {Glass }}\right)$ was calculated based on the assumption that the average of the outside and inside air temperature represented the glass temperature. We calculated the condensation potential based on how far the saturation VD at the glass temperature was below the VD at that height zone inside the rainforest. We scaled the condensation potential in each height zone by its glass surface area to calculate $\mathrm{H}_{2} \mathrm{O}_{\text {Glass. }}$.

\section{Composition and Gas Exchange of Ecosystem Compartments}

The B2-WALD online gas measurement system consisted of multiple instrument streams ( 9 total; here data were derived from instrument streams S1, S2, S3, and S5) (Fig. S9; Table S7) of integrated $\mathrm{CO}_{2}, \mathrm{H}_{2} \mathrm{O}$, and VOC analyzers (as in (53)) to measure atmospheric composition and leaf, stem, and soil fluxes from 56 measurement locations in the ecosystem. The gas analyzers were housed within the TRF mountain feature, predominantly within a climate-controlled shed $\left(\sim 27^{\circ} \mathrm{C}\right)$. Gas sampling was coordinated by automated valves that directed gas through the instrument streams to multi-analyzer sampling loops in the climate-controlled shed. We avoided condensation in gas lines and valves by heating the lines or placing sample selection apparatus in a warm room annexed to the shed. Zero air was centrally generated and used directly (e.g., for instrument reference) or mixed with cylinder gas to generate gas mixtures with controlled composition gas (e.g., inlet gas to leaf chambers, online calibration mixtures). The air was compressed by an in-house oil-free air compressor (Kaeser Compressors Dental, 11 CFM, model Dental 3/2T type 117 769), filtered for impurities and condensation, and purified with a zero air generator (ZAG) (Aadco Instruments, Inc., Cleves, OH. 737-13-C-CH4-120) that removed methane and volatile compounds, as well as $\mathrm{CO}_{2}$ with add-on scrubbers (PureGas, VCD4-12-029). Wherever possible, we used teflon tubing (PFA) and fittings (PFA Swagelok, PEEK IDEX, PEEK VICI ferrules, and PFA Galtek) upstream of VOC analyzers to minimize surface VOC losses and conversions.

\section{Calibration of $\mathrm{CO}_{2}$ and $\mathrm{H}_{2} \mathrm{O}$ isotope analyzers}

We used a Central Calibration Unit (CCU) to provide $\mathrm{CO}_{2}$ and $\mathrm{H}_{2} \mathrm{O}$ in different concentrations and isotopic compositions to calibrate the laser spectrometers (LAS; Table S7) that quantify trace gas concentrations and isotope ratios by infrared absorption spectroscopy. The CCU main air flow (zero air, $1 \mathrm{~L} \mathrm{~min}^{-1}$ through the nebulizer and $4 \mathrm{~L}$ $\mathrm{min}^{-1}$ make-up air) was provided by the ZAG and metered through two Mass Flow Controllers (MFC; Alicat, Tucson, AZ, USA). The nightly CCU procedure covered 14 stages over an 80-minute period (0:00-1:20) that covered a range of $\mathrm{CO}_{2}$ (0 to $\left.1600 \mathrm{ppm}\right)$ and $\mathrm{H}_{2} \mathrm{O}(0$ to $25,000 \mathrm{ppm})$ concentrations crossed with a gradient in isotopic composition (see description below). All five analyzers were switched via 3-way solenoid or multiport valves to sample the common calibration gas. The CCU was controlled by a control system (National Instruments, Austin, TX, USA), and $\mathrm{CO}_{2}$ and $\mathrm{H}_{2} \mathrm{O}$ concentrations were randomly selected, while each of the isotopic compositions were selected sequentially. 
To generate carbon dioxide isotope calibration curves using the CCU, we added different quantities of $5 \%$ $\mathrm{CO}_{2}$ in air (Airgas Inc., Wayne, PA, USA) through MFCs to yield four different $\mathrm{CO}_{2}$ concentrations between 300 and $1500 \mathrm{ppm} \mathrm{CO}_{2}$ in air. This was done for three different isotopic compositions using reference tanks from different geographical regions (La Porte, TX, Tooele, UT, and Phoenix, AZ) that had characteristic $\delta^{13} \mathrm{C}$ values of $\mathrm{CO}_{2}(\sim-10$, -32.8 , and $-38.9 \%$, respectively). Tanks of the most enriched mixture ( -10\%o) from Texas were replaced approximately every two weeks, as the $5 \% \mathrm{CO}_{2}$ was also used to supply leaf mix $\mathrm{CO}_{2}$ (see Leaf Measurements, below). We used LAS-2 (Table S7) and its two internal isotopic composition reference gases (-8 and $-27 \%$, VPDB, Thermo Fisher, Scientific, Germany) to directly calibrate all CCU $\operatorname{tank} \delta^{13} \mathrm{C}$ values.

To generate water isotope calibration curves using the CCU, we metered water of three different $\delta^{2} \mathrm{H}$ values $(\sim-140.3,+25.0$ and $+454.6 \%$ vs VSMOW) into zero air using a micro peristaltic pump (Periwave Milli, CorSolutions, Ithaca, NY, USA). Water was vaporized within a glass nebulizer (High Efficiency Nebulizer, Meinhard, Golden, CO, USA). The metal nebulizer housing and the zero air stream coming into the nebulizer were heated to $150{ }^{\circ} \mathrm{C}$ and 120 ${ }^{\circ} \mathrm{C}$, respectively, to prevent condensation in the chamber. Water concentrations (up to 25,000 ppm $\mathrm{H}_{2} \mathrm{O}$ ) were changed by modulating the peristaltic pump rate, while the hydrogen isotopic composition was changed by selecting different waters with a Valco multiport valve (VICI Valco Instruments, Houston, TX, USA). $\delta^{2} \mathrm{H}$ values of CCU standard waters were determined from liquid samples at the Chair of Ecosystem Physiology, Freiburg using cavity ring-down spectroscopy (L2130i Water Isotope Analyzer, Picarro Inc., Santa Clara, CA, USA), using four house standards $\left(\delta^{2} \mathrm{H}\right.$ values $=-102.8,-63.7,-10.22$, and $+53.9 \%$, VSMOW) cross-calibrated to international standards GISP, SLAP and SMOW (IAEA, Vienna).

Analyzers either directly sampled the CCU on a nightly basis or were cross-referenced to this or other primary calibrations. The S1 nightly CCU procedure was used to account for LAS-1 concentration-dependent offsets between true and observed isotope ratios using $\log _{2}$ and linear functions for ${ }^{13} \mathrm{C}$ and ${ }^{2} \mathrm{H}$ isotopes of $\mathrm{CO}_{2}$ and $\mathrm{H}_{2} \mathrm{O}$, respectively, as a function of their respective bulk concentrations. LAS-1 $\mathrm{CO}_{2}$ concentrations were cross-calibrated with LAS-2 values through simultaneous measurement of the controlled leaf gas mixture $\left(\sim 500\right.$ ppm $\left.\mathrm{CO}_{2}\right)$ throughout the campaign by both instruments (see Leaf Measurements below). For S2, the two internal LAS-2 standards (described above) were diluted with $\mathrm{CO}_{2}$-free ultra-high purity nitrogen gas (Airgas Inc., Wayne, PA, USA) to match the concentration of the sample gas and were used for continuous calibration of the $\delta^{13} \mathrm{C}$ values measured by this analyzer. The LAS-2 internal calibration procedure included isotopic linearity calibration, two-point concentration calibration as well as a two-point $\delta$ scale calibration. The $\mathrm{CO}_{2}$ isotope analyzers of S3 (LAS-4) and S5 (LAS-5) were calibrated to the VPDB scale using the nightly CCU procedure, accounting for span and offset. Concentration measurements of LAS-5 were verified with an external gas standard (1500 ppm $\pm 1 \% \mathrm{CO}_{2}$ in synth. air) measured several times a day. Throughout the experiment, concentration measurements were stable and within the range of uncertainty of that external standard. Concentration measurements by LAS-4 were calibrated (span-offset) using the nightly CCUprocedure.

\section{Calibration of proton transfer reaction time-of-flight mass spectrometry (PTR-TOF-MS) instruments}

Nocturnal calibrations of all proton transfer reaction time-of-flight mass spectrometers (PTR-TOF-MS) were conducted using a liquid calibration unit (LCU, Ionicon Analytik, Austria) supplied by the ZAG and one of two standard gas cylinders containing different multi-VOC component calibration mixtures (Table S8) in Ultra-High Purity (UHP) nitrogen (Apel-Riemer Environmental, Inc., Florida, USA). The LCU delivered the controlled calibration mixture to each PTR-TOF-MS via 3-way valves (Parker Hannifin, Teflon(R), 001-0028-900, Ohio, USA) through $1 / 8$ " PFA tubing heated to $50{ }^{\circ} \mathrm{C}$ with a custom-made heating system. Each night at midnight, all the PTRTOF-MS instruments switched to sample LCU output dynamic calibration 5-step routine for 75 minutes. In order to ensure the full standard equilibration, the gas standard was set to start flowing one hour prior to the start of calibration. The zero air flow rate was held constant (typically $1000 \mathrm{sccm}$ ), while the gas standard flow rate was changed every $15 \mathrm{~min}$ starting from $40 \mathrm{sccm}$ until $0 \mathrm{sccm}$ in $10 \mathrm{sccm}$ steps. The liquid feed of the LCU drew Milli-Q water from a reservoir, which was dynamically nebulized into the evaporation chamber at $20 \mu \mathrm{L} / \mathrm{min}$ to reach a similar humidity level of the calibration mixture as observed in the B2 TRF atmosphere.

The two calibration standard cylinders (Table S8) were used during the campaign to allow explicit calibration of a wide range of species and to evaluate transmission efficiency of the broad $\mathrm{m} / \mathrm{z}$ range. The first cylinder was used for two periods (from 18 September 2019 to 6 November 2019 and from 17 December 2019 to 20 January 2020) to account for any reduction in sensitivity or transmission of the PTR-TOF-MS instruments as a function of detector aging over the campaign. The second cylinder was used from 7 November 2019 to 16 December 2019 to complement the suite of calibrated VOCs.

The ion yields of all $\mathrm{m} / \mathrm{z}$ were measured in counts per second (cps) and compounds were identified from the measured exact mass of their protonated parent ions and isotopic patterns. To account for possible variations of the 
929

930

931

932

933

934

935

936

937

938

939

940

941

942

943

944

945

946

947

948

949

950

951

952

953

954

955

956

957

958

959

960

961

962

963

964

965

966

967

968

969

970

971

972

973

974

975

976

977

978

979

980 reagent ion signals, measured ion intensities were normalized to the $\mathrm{H}_{3} \mathrm{O}^{+}$counts in combination with the water-cluster ion counts (54). All PTR-TOF files were processed using the software PTRwid (55). Data analysis of stream 2 was performed by PTRMS Analysis (PTRMS-analysis.com). Concentrations of compounds not included in the calibration standard cylinders were calculated applying the kinetic theory of proton transfer reaction $(56,57)$.

\section{Atmospheric measurements}

Atmospheric gas concentrations of $\mathrm{CO}_{2}, \mathrm{H}_{2} \mathrm{O}$, and VOCs and selected isotopologues were measured hourly over five-minute intervals at five different heights $(1 \mathrm{~m}, 3 \mathrm{~m}, 7 \mathrm{~m}, 13 \mathrm{~m}$ and $20 \mathrm{~m})$ above the forest floor from the NE tower (S1) and at the outside air inlet to the ecosystem, with duplicate measurements every other hour for heights $3 \mathrm{~m}$ and $13 \mathrm{~m}$ (S2). All sampling lines had a length of $30 \mathrm{~m}$ and were made of $1 / 4$ " OD PFA tubing (Ametek, Nesquehoning, PA, USA) that was protected by inlet filters ( $0.45 \mu \mathrm{m}$ pore size PTFE; EW-02915-31, Cole Palmer, Vernon Hills, IL). Within each five-minute valve interval we averaged two minutes of data (from minute 2.5 to 4.5 ) after quality control filtering.

The isoprene ${ }^{13} \mathrm{C}$ isotope ratio was calculated as the ratio of $\left[{ }^{13} \mathrm{C}\right] \mathrm{C}_{4} \mathrm{H}_{8}$ concentration to $\mathrm{C}_{5} \mathrm{H}_{8}$ concentration and the monoterpene ${ }^{13} \mathrm{C}$ isotope ratio was calculated as the ratio of $\left[{ }^{13} \mathrm{C}\right] \mathrm{C}_{9} \mathrm{H}_{16}$ concentration to $\mathrm{C}_{10} \mathrm{H}_{16} \mathrm{Concentration}_{\text {. }}$ Since both isoprene and monoterpene signals were explicitly calibrated, we assumed that the sensitivities of the ${ }^{12} \mathrm{C}$ and ${ }^{13} \mathrm{C}$ analogue of each VOC were identical. During the nighttime, concentrations of the ${ }^{13} \mathrm{C}$ analogue fell below the MS-1 detection limit, so only daytime isotope ratios are reported. The enrichment of the ${ }^{13} \mathrm{C}$ VOCs shown in Fig. $4 \mathrm{f}$ and $4 \mathrm{~g}$ are the elevated isotope ratios above the background level. The background isotope ratio, with ${ }^{13} \mathrm{C}$ naturally occurring at $1.109 \%$ of all carbon and ${ }^{12} \mathrm{C}$ naturally occurring at $98.89 \%$ of all carbon, was calculated as $1.109 / 98.89$ $=1.112$. As isoprene contains 5 and monoterpenes contain 10 carbon atoms, the background, single-carbon isotope ratio was multiplied by 5 and 10 to find the ${ }^{13} \mathrm{C}$ isoprene and ${ }^{13} \mathrm{C}$ monoterpene isotope ratios, respectively.

\section{Leaf measurements}

Leaf fluxes were measured every hour (S1), every two hours (S2), or every 25 minutes (S7) over five-minute intervals using a total of 30 leaf and empty chambers (S1: 5 chambers, S2: 20 chambers, S7: 5 chambers) (Table S6; Table S7). Custom-built flow-through leaf-chambers were constructed out of FEP film (McMaster Carr, 85905K64, Elmhurst, IL, USA). Structure was provided by copper wire threaded through PFA tubing ( $1 / 8$ " OD; Ametek, PA, USA). Leaf chambers were equipped with a fan (MC25101V2, Sunon, Taiwan) to guarantee effective air mixing and were sealed with terostat (Terostat-II, Kahmann \& Ellerbrock GmbH \& Co. KG, Bielefeld, Germany) on both ends. We generated a controlled gas composition by metering $5 \% \mathrm{CO}_{2}$ in air (using the $\delta^{13} \mathrm{C} \sim-10 \%$ tanks from the CCU) into VOC-free ZAG air. During ${ }^{13} \mathrm{CO}_{2}$ pulse labeling, an additional low flow mass flow controller (MFC) was added

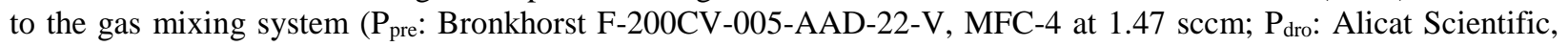
Inc. MC-2SCCM-D/5M re-ranged to MC-4SCCM-D/5M, MFC-50 $3.21 \mathrm{sccm}$ ) at a rate to match the atmospheric ${ }^{13} \mathrm{CO}_{2}$ enrichment (see Ecosystem-Scale Isotope Labeling above). The air was humidified via selectively permeable membrane Nafion tubing, enabling the transfer of water vapor between purified water Barnstead $^{\mathrm{TM}} \mathrm{Nanopure}^{\mathrm{TM}}$, Thermo Fisher Scientific, Dubuque, IA, USA) and the gas stream (MH-110-48F-4; Perma Pure, LLC, Lakewood, NJ, USA). The custom gas mixture was delivered via a distribution manifold (custom aluminum blocks with ports) to 24 MFCs (MC-2SLPM-D/5M, MCS-2SLPM-D-.25NPT/5M; Alicat Scientific, Inc., Tucson, AZ, USA) to continuously flush each of the 25 chambers with $1 \mathrm{~L} \mathrm{~min}^{-1}$ of VOC-free air with $\sim 500 \mathrm{ppm}$ of $\mathrm{CO}_{2}$ and $\sim 2000 \mathrm{ppm}$ of $\mathrm{H}_{2} \mathrm{O}$. For less active leaves the flow was reduced to $0.85 \mathrm{~L} \mathrm{~min}^{-1}$ to increase the leaf signal, while for the biggest leaf (PA4) the flow was increased to $1.45 \mathrm{~L} \mathrm{~min}^{-1}$ to prevent water condensation in the chamber. This approach balanced leaf drying by inlet air against potential condensation of plant-released moisture in sample outlet air. Leaf temperature $\left({ }^{\circ} \mathrm{C}\right)$ and PAR $\left(\mu \mathrm{mol} \mathrm{m} \mathrm{m}^{-2} \mathrm{~s}^{-1}\right)$ were logged for each chamber. Sampling lines were heated to prevent condensation. Over each fiveminute measurement interval, two-minute averages (from minute 2.5 to 4.5) of each $\mathrm{CO}_{2}$ and $\mathrm{H}_{2} \mathrm{O}$ isotopologue were computed.

\section{Calculation of leaffluxes}

The isotopic composition of leaf $\mathrm{CO}_{2}\left(\delta^{13} C_{l} ; \%\right.$, VPBD) and $\mathrm{H}_{2} \mathrm{O}\left(\delta^{2} H_{l} ; \%\right.$, VSMOW $)$ were calculated using isotopic mass balance:

$$
\delta^{13} C_{l}=\left(\delta^{13} C_{0} c_{0}-\delta^{13} C_{e} c_{e}\right) /\left(c_{0}-c_{e}\right)
$$

$\delta^{2} H_{l}=\left(\delta^{2} H_{0} w_{0}-\delta^{2} H_{e} w_{e}-\left(\delta^{2} H_{0}-\delta^{2} H_{e}\right) w_{0} w_{e}\right) /\left(w_{0}-w_{e}\right)$ 
981

982

983

984

985

986

987

988

where $c_{e}$ is the $\mathrm{CO}_{2}$ concentration in the empty chamber, $c_{o}$ is the $\mathrm{CO}_{2}$ concentration at the exit of the leaf chamber, $w_{e}$ is the concentration of water vapor in the empty chamber, $w_{0}$ is the concentration of water vapor at the exit of the leaf chamber, $\delta^{13} C_{0}$ and $\delta^{2} H_{0}$ are the delta values of the air leaving the leaf chamber, and $\delta^{13} C_{e}$ and $\delta^{2} H_{e}$ are values for air measured in the empty chamber.

The mean residence time of ${ }^{13} \mathrm{C}$-tracer in leaf respiration after each atmospheric pulse labeling was calculated from the $\delta^{13} \mathrm{C}$ values of leaf nighttime respiration. An exponential decay model was fitted to the $\delta^{13} \mathrm{C}$ values of leaf respiration. Mean residence time was calculated as the time required to reduce the $\delta^{13} \mathrm{C}$ value of leaf respiration to 1/e of its initial value.

\section{Criteria for functional group assignment}

We assigned all measured canopy-forming trees and understory species into different functional groups regarding their drought susceptibility (drought-tolerant and drought-sensitive) based on their anatomical and hydraulic traits (growth form, specific leaf area, wood density) and functional response to drought (Table S1). The functional drought response was assessed for each individual plant in terms of the magnitude and velocity of changes. Thus, beyond assigning species based on their anatomical traits, we evaluated functional changes of sap flux rates, leaf water potentials, and transit times assessed from labeling with respect to their response velocity during early/late drought and rewet and response magnitude (\% decrease during drought). The analysis revealed that the positioning within the forest strata with different microclimate, in particular light climate and VPD, had a significant impact on the functional response of the different plant individuals. Therefore, grouping was adjusted based on the functional response taking both the species drought adaptation and their environment/positioning within the forest into account, resulting in the four assigned functional groups of drought-tolerant and drought-sensitive canopy-forming trees and drought-tolerant and drought-sensitive understory species as shown in Table S1.

We calculated mean carbon and water fluxes of SF, $\delta^{2} \mathrm{H}_{1}$, pLWP, and mLWP for each functional group, as well as group contributions to the total ecosystem flux. Total water flux was normalized to the pre-drought phase (mean values from 4 October to 7 October). All later periods had lower fluxes and exhibited relative total water flux $<100 \%$. Then, the relative contribution of each functional group to the normalized flux was derived. For SF, daily sums were calculated. $\delta^{2} \mathrm{H}$ values of transpiration $\left(\delta^{2} \mathrm{H}_{\mathrm{t}}\right)$ were derived by averaging $\delta^{2} \mathrm{H}_{1}$ values each day. Smoothing functions were calculated separately for the periods before and after the deep rewet (December 1 - 3, 2019) using locally estimated scatterplot smoothing (predict function, $\mathrm{R}$ version 3.6.0). For continuous data $\left(\mathrm{SF}, \delta^{2} \mathrm{H}_{\mathrm{t}}\right)$ the transit period (December 1 - 3, 2019) was linearly interpolated. In the case of mLWP, the transit time was November 30 - December 3, 2019 (understory) and December 1 - 3, 2019 (canopy). For pLWP, no data were collected directly before rewet (December 1, 2019). Therefore, no interpolation was applied across the transition period.

\section{Soil flux measurements}

Soil fluxes of $\mathrm{CO}_{2}$ and VOCs were measured continuously by an automated soil flux system consisting of a LI8100 infrared gas analyzer (IRGA) and a LI-8150 16-port multiplexer (Licor Inc., Lincoln, NA, USA) and 12 closed dynamic soil flux chambers (LI 8100-104 Long-Term Chambers with opaque lids, Licor Inc.). The chambers were placed on pre-installed PVC-collars (20 cm diameter). Collars were installed in vegetation-free, bare soil several weeks before the start of the measurements. Each chamber measurement lasted for 10 minutes and consisted of 2.5 minutes of pre-purge (chamber open, lines flushed), followed by 6.5 minutes of closure time and 1 minute of post-purge. All 12 chambers were measured consecutively. Hence, each chamber was measured once every two hours. The system volume (chamber volume, tubing, multiplexer and IRGA) was between 6.5 to 7 L. To integrate additional trace gas analyzers to measure soil $\mathrm{CO}_{2}$ fluxes (LAS-4) and soil VOC fluxes (MS-3, Table S7) into the system, a subsample of ca. $100 \mathrm{sccm}$ was directed from the outflow of the LI-8100A and distributed to the different analyzers. To avoid effects of negative pressure in the system, the volume of subsampled air was replaced with an identical volume of inflow of constant air supplied from the CCU. The outflow of subsample and the inflow of make-up gas were controlled with MFCs (Alicat, Tucson, AZ, USA). The gas composition of the CCU makeup gas was measured on Stream 3 for 10 minutes after every measurement cycle. 
1031

1032

1033

1034

1035

1036

1037

1038

1039

1040

1041

1042

1043

1044

1045

1046

1047

1048

1049

1050

1051

1052

1053

1054

1055

1056

1057

1058

1059

1060

1061

1062

1063

1064

1065

1066

1067

1068

1069

1070

1071

1072

1073

1074

1075

1076

1077

1078

1079

1080

1081

1082

1083

1084

1085

1086

\section{Soil Flux Calculations}

We calculated soil $\mathrm{CO}_{2}$ efflux rates with linear and exponential models, fitted to each individual chamber measurement. We omitted the first $30 \mathrm{~s}$ after chamber closure to allow for mixing in the just-closed chamber. For the linear models we used the first $120 \mathrm{~s}$ after chamber closure, and for the exponential models the full closure time. The exponential model is formulated as

$$
c(t)=c_{\infty}+\left(c_{0}+c_{\infty}\right) e^{-\alpha\left(t-t_{0}\right)}
$$

where $\mathrm{c} 0$ is the starting concentration, $\mathrm{t}$ is time, and t0 the time of chamber closure. The efflux is derived from $\mathrm{dc}(\mathrm{t}) / \mathrm{dt}$ at $\mathrm{t} 0$. In cases where the algorithm failed to fit the exponential model, flux rates derived from linear models were used.

To calculate $\delta^{13} \mathrm{C}$ values of soil-respired $\mathrm{CO}_{2}$ we used the Keeling plot approach with model I linear regression (56). The first $30 \mathrm{~s}$ of each observation were excluded. Quality of $\mathrm{CO}_{2}$ fluxes and $\delta^{13} \mathrm{C}$ values were checked visually and outliers were removed prior to further analysis. $\mathrm{CO}_{2}$-fluxes and $\delta^{13} \mathrm{C}$ values of $\mathrm{CO}_{2}$ were aggregated to daily mean values for each soil chamber.

We calculated soil VOC fluxes by applying the linear regression model to the VOC concentrations obtained during the enclosed measurement period of each chamber. We omitted the first $30 \mathrm{~s}$ after chamber closure to allow for mixing in the just-closed chamber. The linear regression was applied to the successive 12 data points collected at $10 \mathrm{~s}$ intervals. The slope of the linear regression was divided by chamber area, and a time factor to convert the results to hourly units.

\section{Stem flux measurements}

Stem respiration and the $\delta^{13} \mathrm{C}$ values of respired $\mathrm{CO}_{2}$ were measured continuously from 12 trees (Table S6) using a custom-made automated setup coupling steady-state flow-through stem respiration chambers to a carbon isotope analyzer (LAS-5, Table S7). The chambers were built with similar material as the leaf chambers (see Leaf measurements, above). They covered a base area of c. 15 x $20 \mathrm{~cm}^{2}$. For three trees with a small circumference (Table S1) the chambers enclosed the full stem of the tree. Chambers were attached at approx. $50 \mathrm{~cm}$ height with tension straps around the tree stem and sealed with terostat. Each chamber had a thick inlet tube (3/4"' OD) and an outlet tube (1/4', OD). The chamber inlet tube had a length of $50 \mathrm{~cm}$ and was open to ambient air around the stem. The outlet tube was connected to the multiplexing unit. At each chamber an additional gas line sampled rainforest air in direct proximity to characterize the chamber inlet composition. All chambers were continuously flushed by a central flush pump to maintain steady-state conditions inside the chambers. The flow rate in each chamber was maintained at $\sim 200$ sccm and logged continuously. The multiplexer switched between chamber inlets and outlets and directed the sample gas to the $\mathrm{CO}_{2}$ analyzer. Each individual measurement consisted of $240 \mathrm{~s}$ of outlet measurement, framed by $180 \mathrm{~s}$ of inlet measurements before and after. All 12 chambers were measured consecutively, resulting in a temporal resolution of approx. 2 hours. After every second measurement cycle an external gas standard was measured for $240 \mathrm{~s}$ on the gas analyzer.

\section{Stem Flux Calculations}

Stem $\mathrm{CO}_{2}$ efflux and its $\delta^{13} \mathrm{C}$ value were calculated using two-way mixing models.

$$
\begin{gathered}
R_{\text {stem }}=u\left(\mathrm{CO}_{2 \text { out }}-\mathrm{CO}_{2 \text { in }}\right) / \mathrm{SA} \\
\delta^{13} C_{\text {stem }}=\left(\delta^{13} C_{\text {out }} * C \mathrm{C}_{2 \text { out }}-\delta^{13} C_{\text {in }} * C O_{2 \text { in }}\right) /\left(\mathrm{CO}_{2 \text { out }}-\mathrm{CO}_{2 \text { in }}\right)
\end{gathered}
$$

$\mathrm{CO}_{2}$ and $\delta^{13} \mathrm{C}$ denote the average concentrations and carbon isotopic compositions of chamber inlets and outlets, $\mathrm{u}$ is the molar flow and SA the stem surface area of each chamber. The first $110 \mathrm{~s}$ of each inlet and $210 \mathrm{~s}$ of each outlet measurements were omitted to ensure steady-state conditions during the averaging period. Measurements of each individual chamber were visually quality-controlled for outliers. Data was aggregated to average daily flux rates and isotopic compositions prior to further analysis.

Mean residence time of ${ }^{13} \mathrm{CO}_{2}$ in stem-respired $\mathrm{CO}_{2}$ after the two labeling pulses was calculated for each tree by fitting exponential and polynomial decay models to the $\delta^{13} \mathrm{C}$ values of stem $\mathrm{CO}_{2}$ efflux. Only efflux data of the signal decay (after the maximum isotopic enrichment) was used. Polynomial models were only used when the exponential function could not be fit. Mean residence time was calculated as the time required to reduce the $\delta^{13} \mathrm{C}$ value to $1 / \mathrm{e}$ of its maximum value. 
1087

1088

1089

1090

1091

1092

1093

1094

1095

1096

1097

1098

1099

1100

1101

1102

1103

1104

1105

1106

1107

1108

1109

1110

1111

1112

1113

1114

1115

1116

1117

\section{Data storage and sharing}

Every 15 minutes, air measurements from tower sensors were stored on centralized CR1000 data loggers (Campbell Scientific, Logan, UT, USA) with AM16/32B multiplexers (Campbell Scientific, Logan, UT, USA). The tower data loggers were connected to a centralized database with NL100 communications modules (Campbell Scientific, Logan, UT, USA). Data from the centralized database is freely available through the B2 website (www.biosphere2.org/data-models/rainforest-data). Rainforest control (AHU operation, flow through, and louver) data was automatically downloaded every 15 minutes and freely available through the B2 website (https://biosphere2.org/content/rainforest-scada-data), as is outside air temperature and moisture content data (https://biosphere2.org/research/outdoor-weather-station-data).

Sap flux, soil water content, soil matric potential, and tree water content measurements were logged every 15 minutes using SDI-12 protocols on separate CR1000 data loggers. Tree and soil pit data were manually downloaded and uploaded to a central team database. For all other instruments, data was stored on the computer operating the instrument and uploaded on a weekly basis to a central Google drive.

\section{Statistics}

Leaf-level fluxes in the weeks of each pulse labeling (maximum daytime NEE and maximum nighttime respiration calculated as largest $10 \%$ and smallest $25 \%$ of measured fluxes of each tree in each week, respectively) and leaf ${ }^{13} \mathrm{C}$ content after each labeling were tested using linear mixed effect models. Drought, plant strategy (sensitive/tolerant) and canopy strata (canopy/understory) and the interactions of drought:strata and drought:strategy were tested as fixed effects, and individual trees were set as random intercept. Mean residence times of labeled ${ }^{13} \mathrm{C}$ stem respiration was tested with drought, plant strategy and their interaction as fixed effects. Mean residence of leaves were grouped across plant strategies and strata and tested for drought as fixed effect. Response variables were squareroot or log-transformed where necessary to meet model assumptions and $\delta^{13} \mathrm{C}$ values were transformed to atom fraction to allow data transformation. Statistical analysis was done in R. Linear mixed effect models were calculated using the package 'nlme'(59).

Leaf- and stem respired ${ }^{13} \mathrm{C}$ were tested for the effects of drought, plant strategy and canopy strata and the interactions of drought and plant strategy and drought and canopy strata using generalized additive models (GAM) and the R-package 'mgcv' (60). The smooth term accounted for the temporal dynamics of the response of each individual tree, with a maximum of eight knots. For all GAMs the methods were set to 'REML', smoothing basis to 'fs' and the family to 'scat'. 


\section{Science}

DIAAAS

1118

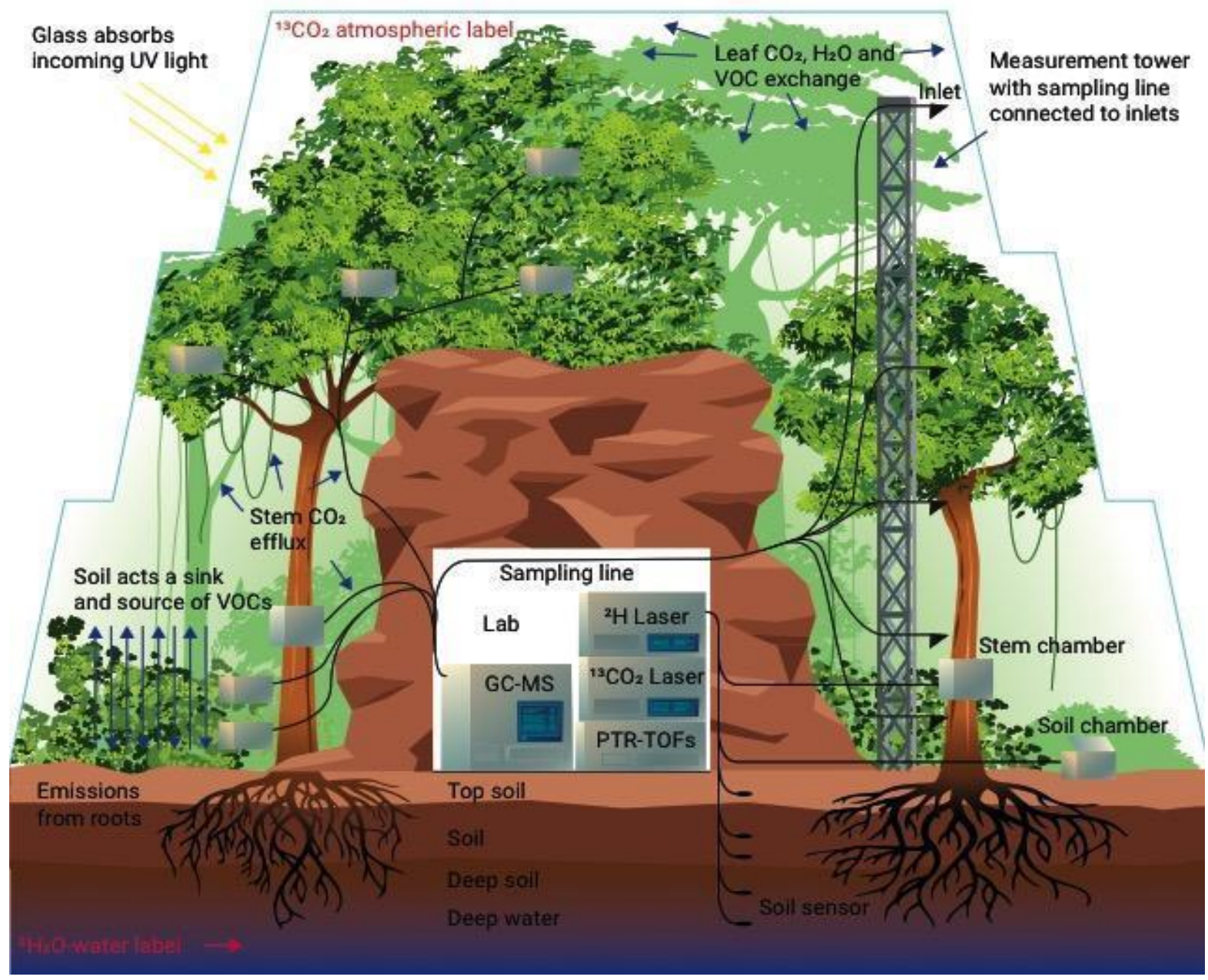

1121 Fig. S1. Illustration of Experimental Setup in the Biosphere 2 tropical rainforest. For measuring systems and 


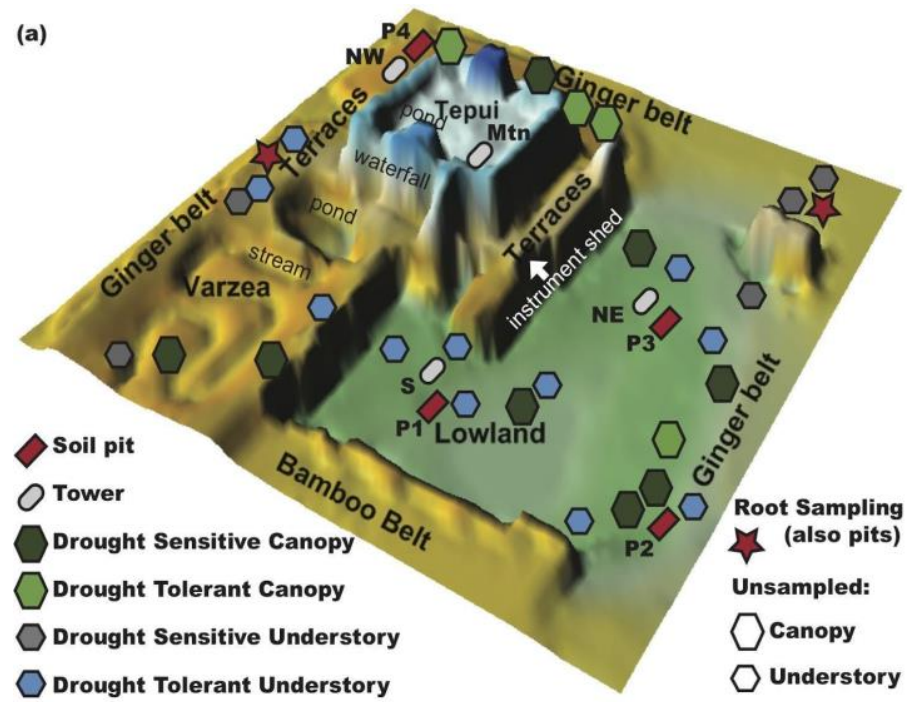

(b)

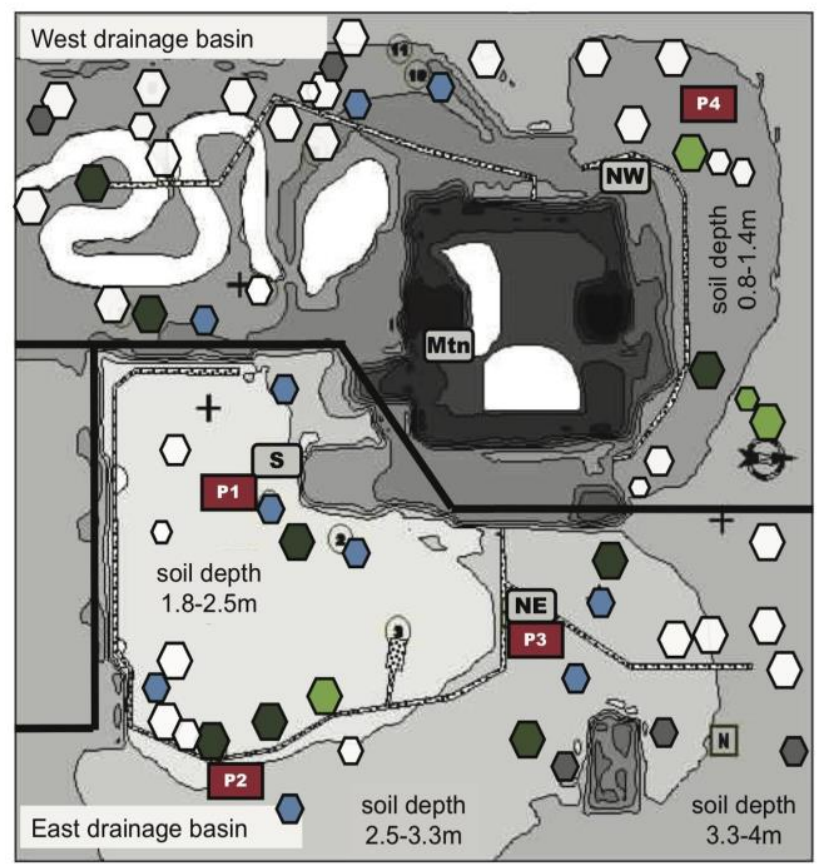

Fig. S2. Biosphere 2 tropical rainforest. (a) Topographical 3D rendering of rainforest zones and the location of water features, instrument shed, soil pits (P1 - P4), atmospheric sampling towers (NW = Northwest tower; NE = Northeast tower; Mtn = Mountain tower; $\mathrm{S}=$ South tower), and plants investigated. (b) Overhead 2D projection of the same features, including locations of unsampled plants (white symbols), soil depth ranges (grey shading and thin contour lines), and delineation (thick black line) between the East and West drainage basins. Soil flux chambers were installed near each of the four soil pits. Root samples were collected near each soil pit (red rectangles) and at two additional locations (red stars). 
MIAAAS

1137

1138

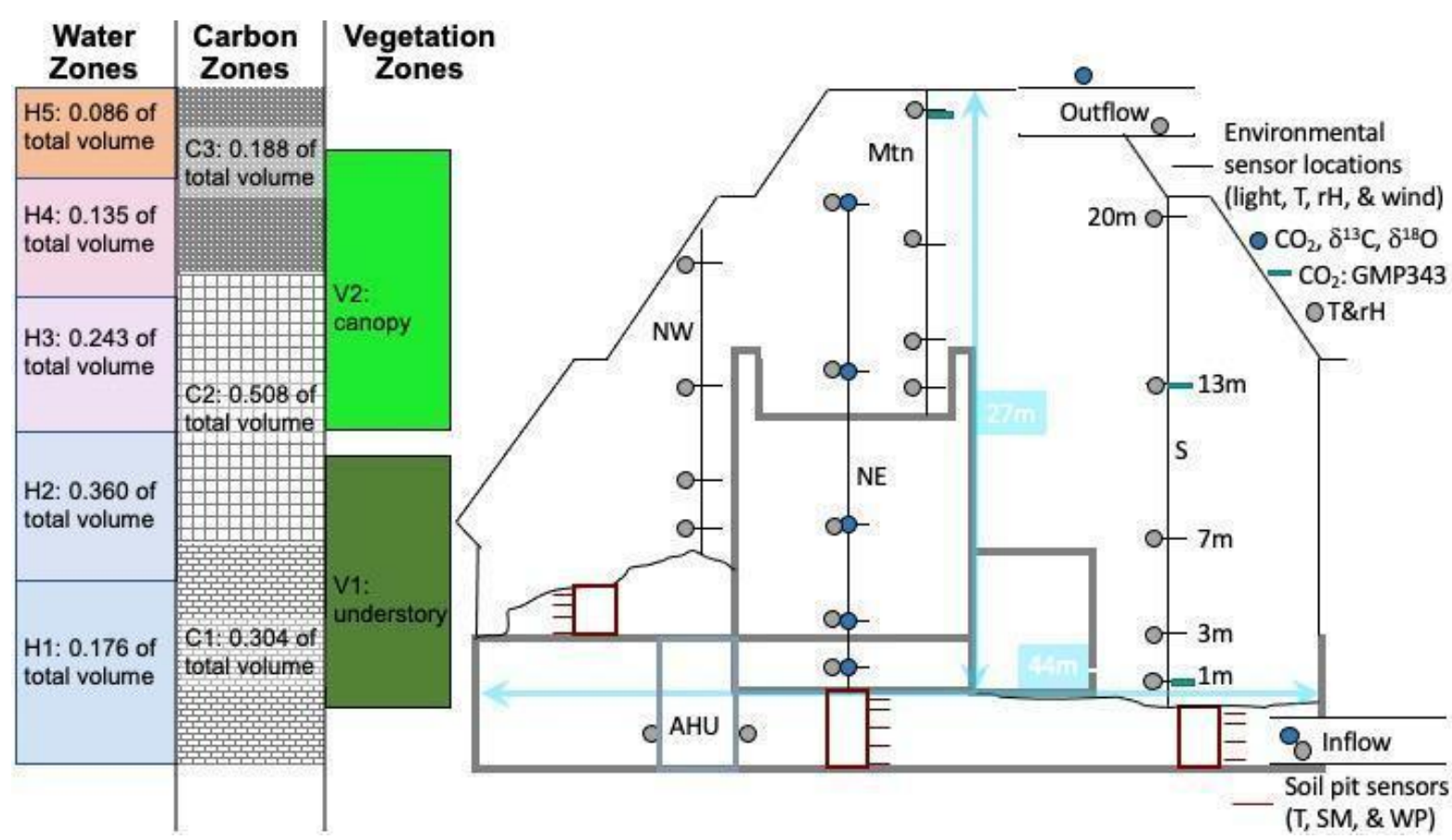

Fig. S3. Cross-section of the Biosphere 2 tropical rainforest with the environmental and $\mathrm{CO}_{2}$ sensor locations as well as the air sampling locations for isotope and VOC measurements. At left the different color shadings indicate the height zones (H1-5) used for water budget calculations, different hatch marks indicate the height zones (C1-3) for the $\mathrm{CO}_{2}$ budget, and the different green color shadings indicate the vegetation height zones (V1 and V2). AHU - air handler unit. Mtn - mountain tower, NE, NW, S - tower orientation in B2. T - temperature, $\mathrm{rH}$-relative humidity. 


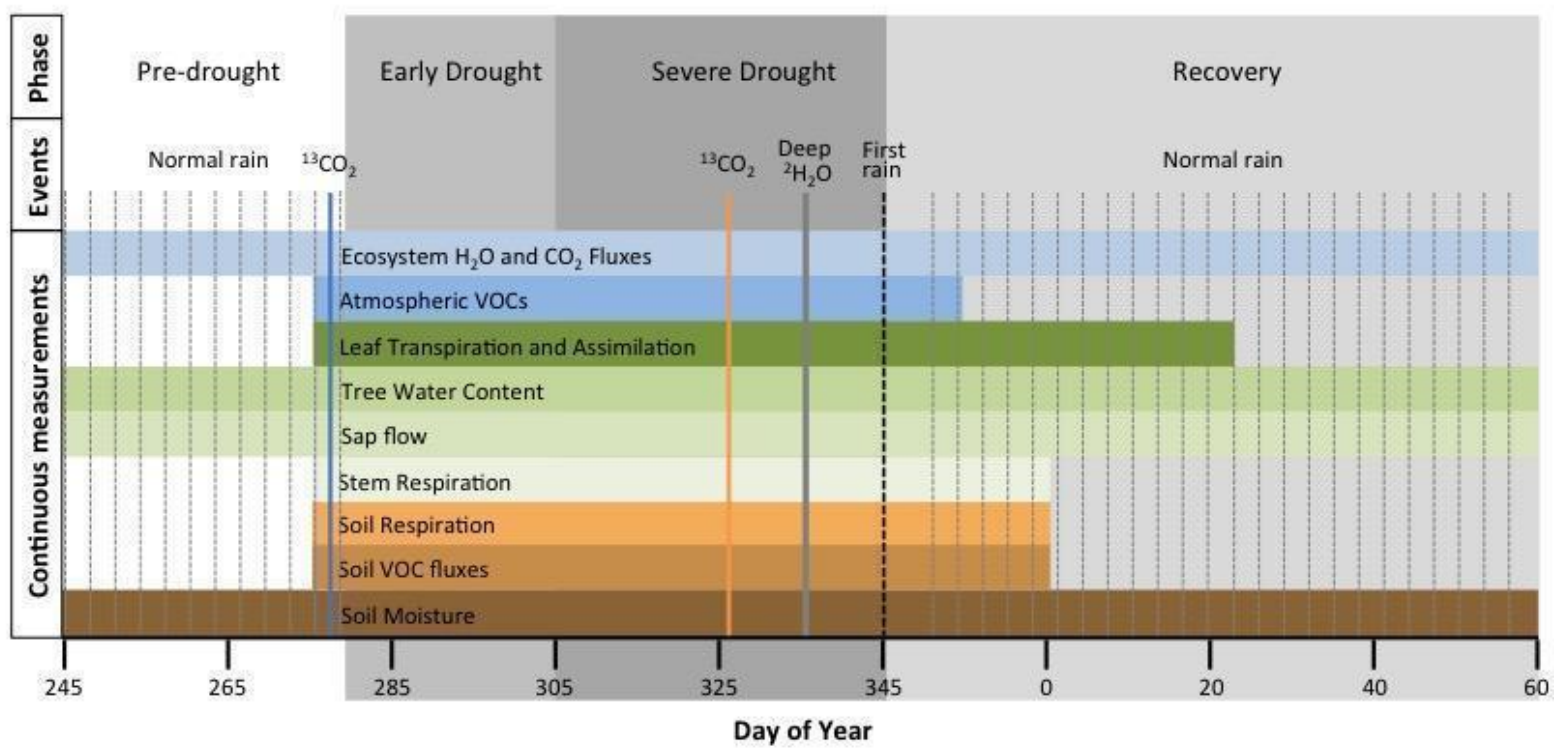

Fig. S4. Schematic overview of the experimental timeline, significant events, and continuous measurements. Regularly scheduled rain events (light dashed lines) occurred three times per week before in the pre-drought period. The early drought phase began with the first skipped rain event and lasted until the initial period of topsoil drying was complete. The severe drought phase lasted until the first rain event. We waited one week after the first rain before returning to the normal rain schedule (three events per week). We conducted ecosystem-scale ${ }^{13} \mathrm{CO}_{2}$ pulse labels in the pre-drought (solid blue line) and during the severe drought (solid orange line). We introduced ${ }^{2} \mathrm{H}_{2} \mathrm{O}$ to the deep water late in the severe drought (solid gray line). 


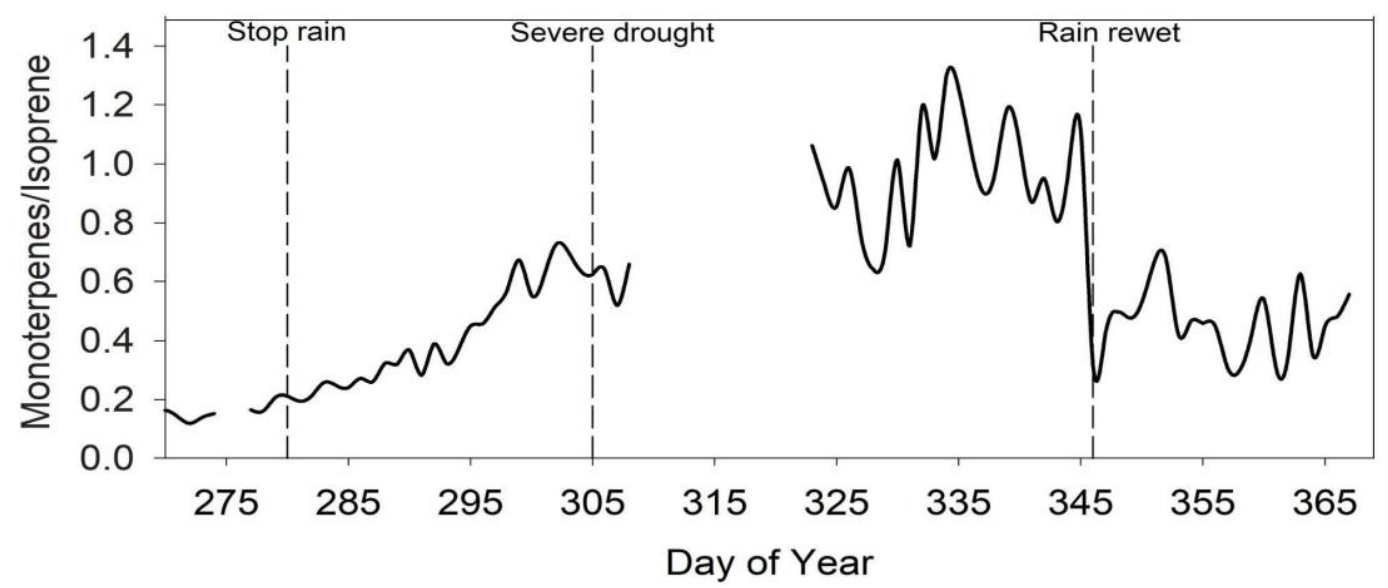

1160

1161

1162

1163

1164

1165

1166

1167

1168

1169

Figure S5. Soil VOC dynamics. Ratio of the soil deposition velocity (atmospheric concentration-normalized flux) of monoterpenes to that of isoprene shows an increase in the soil sink capacity for monoterpenes relative to isoprene in drought, independent of differences in real time VOC substrate availability (atmospheric concentration). This shift could reflect a greater drought sensitivity of the isoprene harvesting microbial community compared to those that use monoterpenes and/or a concordant shift in microbial VOC metabolisms with plant-controlled shifts in atmospheric availability, which is immediately reversed upon surface rewet. 
1170

1171

1172

1173

1174

1175

1176

1177

1178

1179

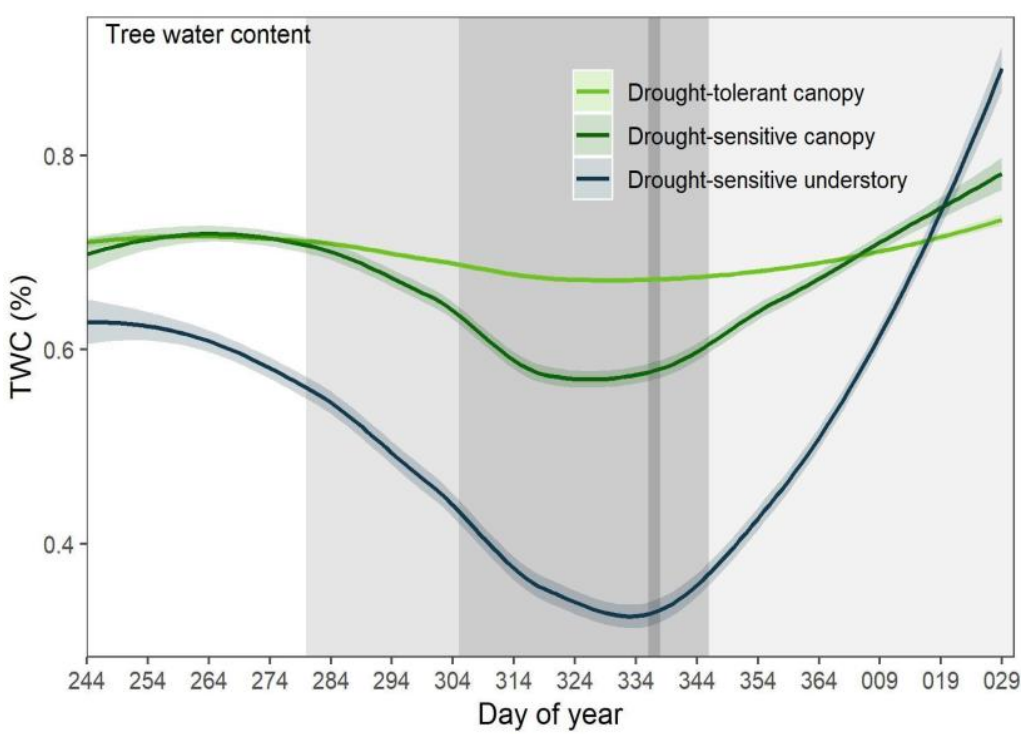

Figure S6. Tree water content (TWC, \%) over time (Day of year), grouped by plant functional group (n = 2-6 per functional group). Shaded areas indicate the experiment's phases (Fig S4). Note: no data were available for TWC of drought tolerant understory. More information on data input and grouping in Supplementary Table S1 and in Functional grouping section of methods. 

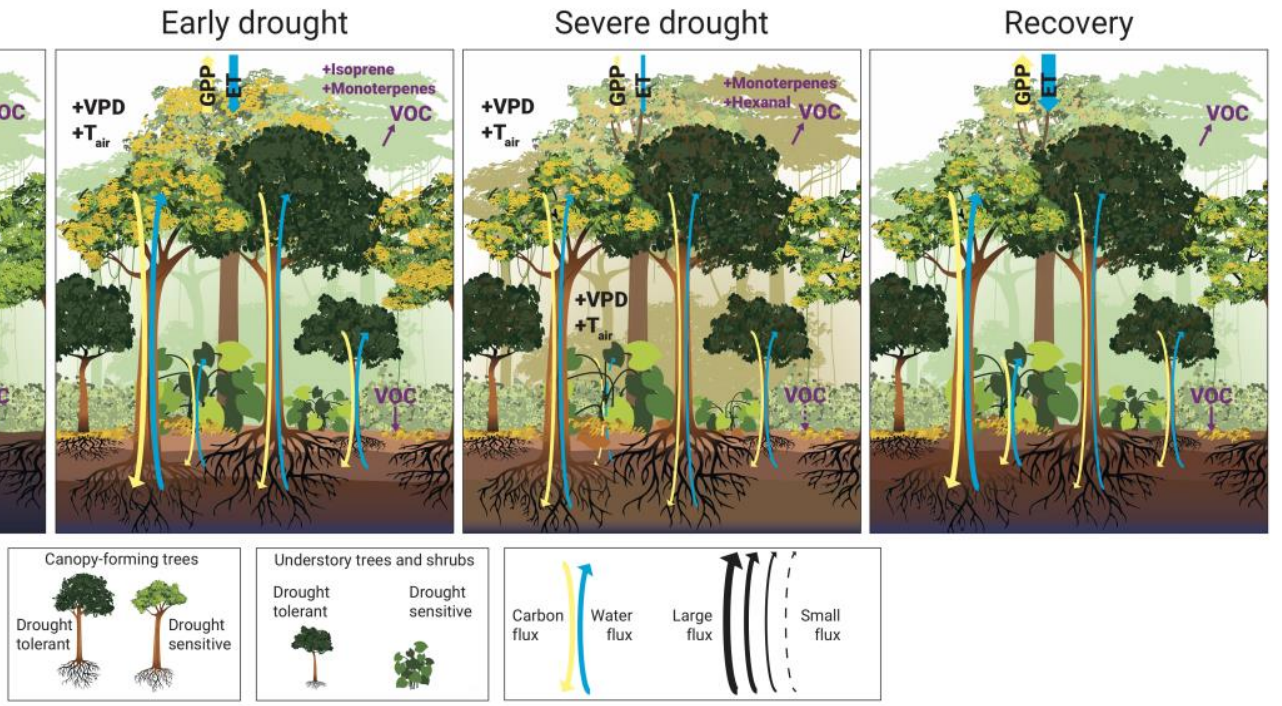

Fig. S7 Schematic ecosystem drought response indicating main processes and key drivers. Under pre-drought conditions, drought-sensitive canopy trees provide the largest contribution to total ecosystem water and carbon fluxes. Soils exhibit high net uptake of VOCs, many of which are produced in the canopy. In early drought, surface soils dry, canopy VPD increases, and plants reduce their carbon and water fluxes, with the largest reductions by drought sensitive-canopy trees. Atmospheric isoprene concentrations increase, followed by an increase in monoterpenes, while the soil becomes a more efficient monoterpene sink. In severe drought atmospheric monoterpene concentrations remain high and hexanal concentrations increase. Meanwhile, understory VPD increases to moderately high values, and the deep soil finally dries out. Ecosystem fluxes of carbon and water reach their lowest values, with the greatest individual reductions by drought-sensitive plants. Drought-tolerant plants thus become relatively more important for overall ecosystem fluxes as the drought progresses. Finally, following the reintroduction of rain, fluxes of water, carbon, and VOCs slowly recover but not to pre-drought levels for most parameters. The prolonged legacy effects of the drought are driven by slow plant hydrological recovery, reduced leaf biomass from drought-sensitive trees, and sustained reductions in soil respiration. 
A Ambient

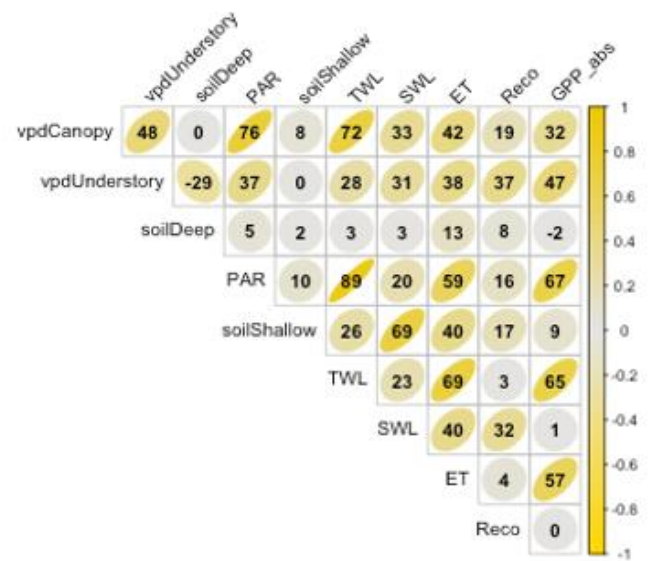

\section{Severe drought}

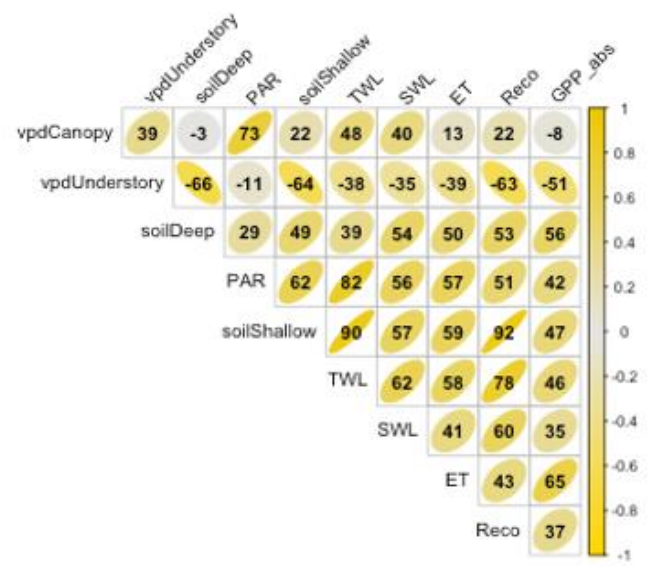

\section{B Early drought}

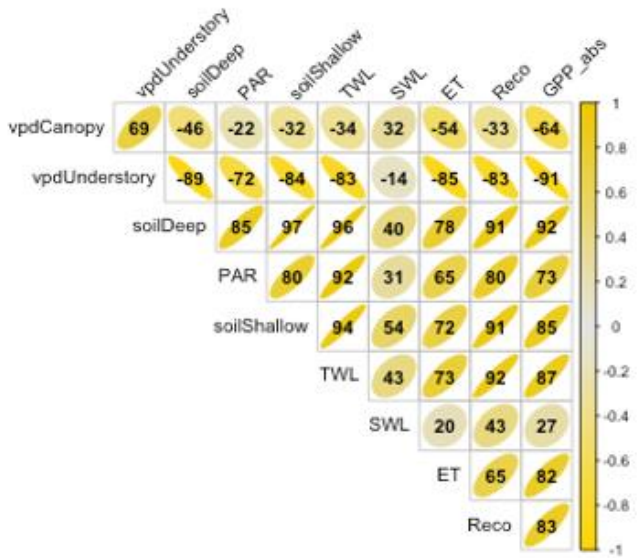

\section{Recovery}

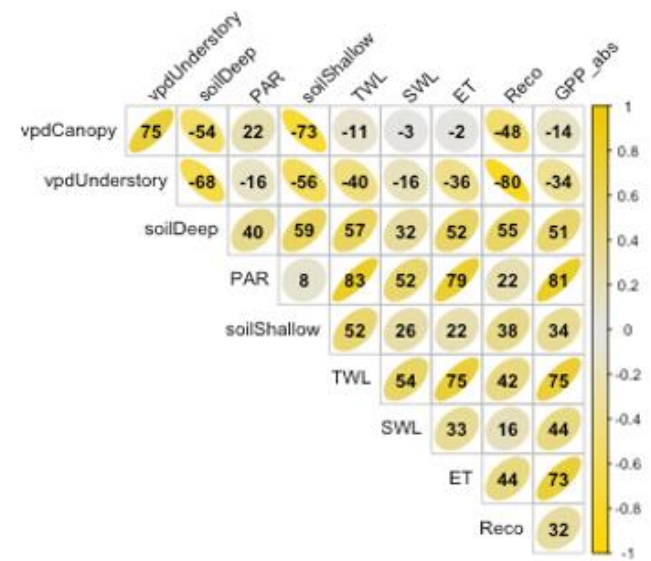

1196
Figure S8. Correlation matrix for ecosystem fluxes and environmental drivers in each experimental phase. Colors denote strength and direction of the correlation; non-significant correlations are crossed-out (significance level $<0.05$ ). Note that GPP is shown with a positive sign here. Correlations are based on Pearson's correlation coefficient. Abbreviations: soilDeep $=$ matric potential in deep soil layers, shoilShallow $=$ matric potential in shallow soil layers, $\mathrm{TWL}=$ tree water loss, $\mathrm{SWL}=$ soil water loss, $\mathrm{ET}=$ evapotranspiration, $\mathrm{PAR}=$ photosynthetic active radiation, Reco = ecosystem respiration, GPP_abs = gross primary productivity (positive sign), vpdCanopy = vapor pressure deficit in canopy, vpdUnderstory = vapor pressure deficit in understory. See Material \& Methods for details. 


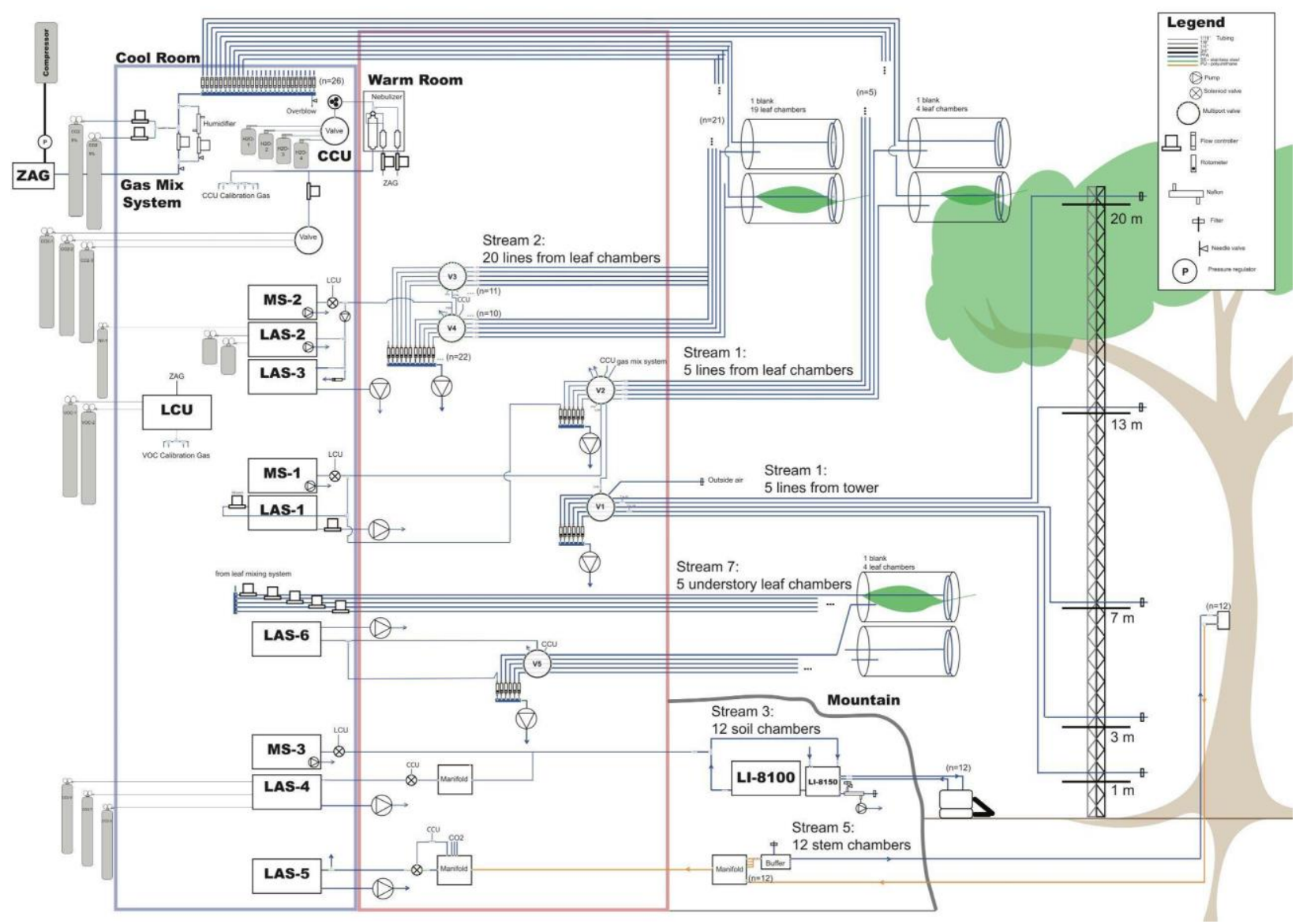

Fig. S9. Instrument system diagram illustrating the measurement streams and gas analyzers (Table S7) and automated gas mix systems for leaf gases and online calibration ( $\mathrm{LCU}$ and $\mathrm{CCU}$ ). $\mathrm{CCU}-$ calibration unit for $\mathrm{CO}_{2}$, water concentration and isotopic composition, LAS - laser spectrometer; Li-8100 Licor gas analyser; LCU - liquid 1211 calibration unit for VOCs, ZAG - zero air generator. 
Table S1. Plant individuals and characteristics that were used when assigning functional groups: drought-sensitive canopy (SC), drought-tolerant canopy (TC), drought-sensitive understory (SU), drought-tolerant understory (TU). DBH = diameter at breast height; LWP = leaf water potential.

\begin{tabular}{|c|c|c|c|c|c|c|c|c|c|c|c|c|c|}
\hline Species & $\begin{array}{l}\text { 国 } \\
\frac{\bar{E}}{\underline{E}}\end{array}$ & 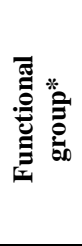 & 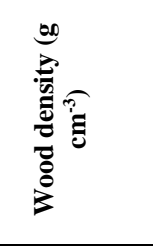 & 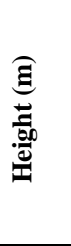 & 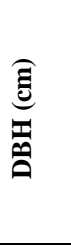 & 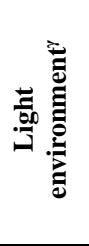 & 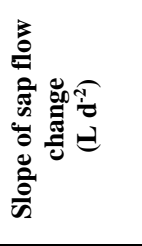 & 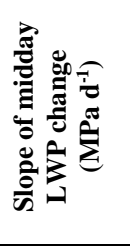 & 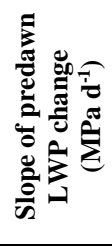 & 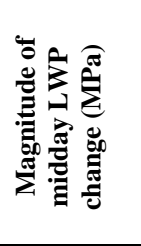 & 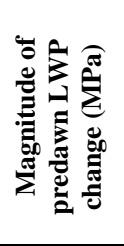 & 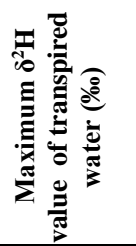 & 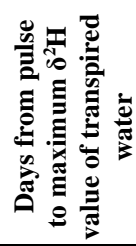 \\
\hline \multirow[t]{4}{*}{ Clitoria fairchildiana } & $\mathrm{CF} 2$ & $\mathrm{SC}$ & $0.54 \pm 0.05$ & 18 & 30.2 & 5 & -0.117 & -0.002 & -0.006 & -1 & -0.65 & 697 & 13 \\
\hline & $\mathrm{CF} 3$ & SC & $0.53 \pm 0.06$ & 20 & 24.5 & 5 & $\begin{array}{l}-1.285 \\
-0.365^{\#}\end{array}$ & 0.001 & -0.015 & -0.7 & -0.85 & 201 & 12 \\
\hline & CF4 & $\mathrm{SC}$ & $0.53 \pm 0.05$ & 25 & 22 & 4 & $\begin{array}{r}-0.240 ;- \\
0.113^{\#}\end{array}$ & -0.017 & -0.003 & -1.03 & -0.82 & 227 & 15 \\
\hline & CF5 & $\mathrm{SC}$ & $0.55 \pm 0.03$ & 23 & 25.9 & 4 & -0.321 & -0.031 & -0.030 & -1.13 & -1.35 & 300 & 16 \\
\hline Ceiba pentandra & $\mathrm{CP} 1$ & $\mathrm{TC}$ & $0.24 \pm 0.03$ & 20 & 36.1 & 5 & -0.026 & 0.008 & 0.002 & -0.15 & & 187 & 34 \\
\hline Hibiscus tiliaceus & HT1 & $\mathrm{SC}$ & $0.50 \pm 0.03$ & 25 & 29.3 & 5 & -0.631 & -0.017 & -0.024 & -1.83 & -1.05 & 801 & 10 \\
\hline Hura crepitans & $\mathrm{HC} 1$ & $\mathrm{SC}$ & $0.41 \pm 0.04$ & 20 & 47.3 & 5 & -0.027 & -0.023 & -0.022 & -0.62 & & 749 & 17 \\
\hline \multirow[t]{5}{*}{ Pachira aquatica } & PA2 & TU & $0.32 \pm 0.04$ & 8 & 12.5 & 2 & 0.001 & 0.008 & -0.018 & 0.17 & -0.87 & -29 & 12 \\
\hline & PA3 & $\mathrm{TU}$ & $0.19 \pm 0.05$ & 6 & 12.5 & 2 & -0.001 & & & & & -12 & 13 \\
\hline & PA4 & $\mathrm{TC}$ & $0.37 \pm 0.03$ & 16.5 & 30.0 & 4 & -0.012 & -0.006 & -0.007 & -0.75 & -0.45 & 145 & 18 \\
\hline & PA6 & $\mathrm{TU}$ & $0.26 \pm 0.04$ & 4 & & 2 & & -0.003 & -0.006 & & & & \\
\hline & PA7 & $\mathrm{TU}$ & $0.29 \pm 0.05$ & 5 & 8.1 & 2 & & & & & & 22 & 13 \\
\hline \multirow[t]{4}{*}{ Phytolacca dioica } & PD1 & $\mathrm{TC}$ & $0.17 \pm 0.01$ & 14 & 35.8 & 4 & -0.016 & -0.014 & -0.011 & -0.817 & -0.53 & 182 & 34 \\
\hline & PD2 & $\mathrm{TC}$ & $0.17 \pm 0.02$ & 13 & 12 & 3 & & -0.007 & -0.024 & -0.95 & -1.2 & 163 & 45 \\
\hline & PD3 & TC & $0.12 \pm 0.02$ & $6^{\$}$ & 24.4 & 4 & & 0.003 & 0,919 & -0.32 & -0.25 & 2 & 25 \\
\hline & PD4 & $\mathrm{TC}$ & $0.13 \pm 0.01$ & 10 & 22.7 & 5 & & 0.018 & -0.004 & -0.37 & -0.67 & & \\
\hline \multirow[t]{8}{*}{ Hibiscus rosa sinensis } & HR1 & $\mathrm{TU}$ & $0.42 \pm 0.01$ & 3.7 & & 1 & -0.001 & 0.021 & -0.012 & -1.03 & -0.48 & -17 & 14 \\
\hline & HR2 & TU & $0.42 \pm 0.01$ & 3.7 & & 1 & -0.001 & -0.019 & -0.017 & -1.08 & -0.88 & 9 & 12 \\
\hline & HR3 & SU & & 3.5 & & 3 & -0.013 & -0.021 & -0.032 & -0.99 & -1.46 & & \\
\hline & HR4 & SU & & 8.5 & & 3 & & -0.016 & -0.036 & -2.6 & -2.33 & & \\
\hline & PI1 & SU & & 4 & 3 & 3 & & & & & & 3 & 46 \\
\hline & PI2 & SU & & 4 & 3 & 3 & & & & & & 66 & 17 \\
\hline & PI3 & SU & & 4 & 3 & 3 & & & & & & 46 & 41 \\
\hline & PI4 & $\mathrm{TU}$ & & 4 & 3 & 1 & & & & & & 22 & 17 \\
\hline Costus sp. & $\mathrm{CO} 1-4$ & TU & & $\sim 1$ & 2 & 1 & & & & & & & \\
\hline
\end{tabular}

* Functional group categories: drought-sensitive canopy (SC), drought-tolerant canopy (TC), drought-sensitive understory (SU), drought-tolerant understory (TU).

$\gamma$ Light environment categories: always shaded $=1 ;$ mostly shaded $=2 ;$ moderately shaded $=3 ;$ slightly shaded $=4 ;$ unshaded $=5$

\# Measurements from sap flow sensors in two stems of tree

$\$$ Although height of PD3 $<10 \mathrm{~m}$, the base is located in the elevated varzia (Fig. S2) and the crown reaches the lower limits of the canopy 
1

2

Table S2. Effects of campaign (ambient/drought), plant strategy (sensitive/tolerant), forest strata (canopy/understory) and the interactions on maximum daytime leaf-assimilation fluxes $\left(\mathrm{A}_{\max }\right)$ and maximum leaf nighttime respiration $\left(\right.$ Resp $\left._{\max }\right)$ in the weeks of the labeling campaign and on bulk leaf $\delta^{13} \mathrm{C}$ values after the labeling. F-values derived from linear mixed effect models, nominator and denominator degrees of freedom are given in subscripts. Superscripts represent respective $\mathrm{p}$-values. Bold values $\mathrm{p}<.05$, italic values $\mathrm{p}<0.1$

\begin{tabular}{|c|c|c|c|}
\hline Fixed effect & Leaf $A_{\max }$ & Leaf Resp $\max$ & Bulk Leaf $\delta^{13} \mathrm{C}$ \\
\hline Campaign & $F_{1,63}=197.17952^{<.0001}$ & $F_{1,75}=105.11013^{<.0001}$ & $F_{1,114}=13^{0.0005}$ \\
\hline Strategy & $F_{1,11}=0.08086^{0.7814}$ & $F_{1,11}=0.01166^{0.9159}$ & $F_{1,15}=6^{0.0306}$ \\
\hline Strata & $F_{1,11}=4.20975^{0.0648}$ & $F_{1,11}=1.71089^{0.2175}$ & $F_{1,15}=2^{0.1749}$ \\
\hline Campaign:Strategy & $F_{1,63}=2.04284^{0.1579}$ & $\mathrm{~F}_{1,75}=0.85557^{0.3579}$ & $F_{1,114}=1^{0.2562}$ \\
\hline Campaign:Strata & $F_{1,63}=0.4405^{0.5093}$ & $F_{1,75}=1.90155^{0.172}$ & $F_{1,114}=3^{0.0659}$ \\
\hline
\end{tabular}


11

12

13

14

15

Table S3. Effects of campaign (ambient/drought), plant strategy (sensitive/tolerant), forest strata (canopy/understory) and their interactions on leaf- and stem-respired $\delta^{13} \mathrm{C}$ values in the chase periods of the two pulse labeling campaigns. Chi-square values derived from generalized additive models. Superscripts represent respective p-values. Bold values $\mathrm{p}<.05$.

\begin{tabular}{lll}
\hline Fixed effect & Leaf-respired $\delta^{13} \mathrm{C}$ & Stem-respired $\delta^{13} \mathrm{C}$ \\
\hline Campaign & $\chi^{2}=152.836^{<0.001}$ & $\chi^{2}=260.624^{<0.001}$ \\
Strategy & $\chi^{2}=0.308^{0.57898}$ & $\chi^{2}=0.025^{0.873}$ \\
Canopy & $\chi^{2}=0.69^{0.40619}$ & \\
Campaign:Strategy & $\chi^{\mathbf{2}}=\mathbf{1 0 . 2 5 5 ^ { 0 . 0 0 1 3 6 }}$ & $\chi^{\mathbf{2}=16.079^{<0.001}}$ \\
& $\chi^{\mathbf{2}}=\mathbf{3 2 . 9 2 6 ^ { < 0 . 0 0 1 }}$ & \\
\hline
\end{tabular}

16

17

18 
19

20

21

22

23

Table S4. Effects of campaign (ambient/drought), plant strategy (sensitive/tolerant) and their interaction on the mean residence time of ${ }^{13} \mathrm{C}$ in leaf- and stem-respiration and the days between labeling and maximum $\delta^{13} \mathrm{C}$ values in stem efflux. F-values derived from linear mixed effect models, nominator and denominator degrees of freedom are given in subscripts. Superscripts represent respective p-values. Bold values $\mathrm{p}<.05$, italic values $\mathrm{p}<0.1$.

\begin{tabular}{|c|c|c|c|}
\hline Fixed effect & MRT Leaf & MRT Stem & Max Stem \\
\hline Campaign & $F_{1,12}=3.892217^{0.072}$ & $F_{1,6}=12.45241^{0.0124}$ & $F_{1,7}=16.61777^{0.0047}$ \\
\hline Strategy & & $F_{1,7}=0.16691^{0.6951}$ & $F_{1,7}=0.07073^{0.7979}$ \\
\hline Campaign:Strategy & & $F_{1,6}=0.74915^{0.42}$ & $F_{1,7}=0.01622^{0.9022}$ \\
\hline
\end{tabular}

24

25

26 
27 Table S5. Mean ranges of environmental conditions during the different drought phases.

28

\begin{tabular}{|c|c|c|c|c|c|c|c|c|c|c|c|c|}
\hline \multirow[b]{2}{*}{ Zone $^{1}$} & \multicolumn{3}{|c|}{ Pre-drought } & \multicolumn{3}{|c|}{ Early Drought } & \multicolumn{3}{|c|}{ Severe Drought } & \multicolumn{3}{|c|}{ Recovery } \\
\hline & Und & Can & Out & Und & Can & Out & Und & Can & Out & Und & Can & Out \\
\hline $\mathrm{T}_{\text {day }}\left[{ }^{\circ} \mathrm{C}\right]^{2}$ & $\begin{array}{c}26.6 \\
\mid \\
21.3\end{array}$ & $\begin{array}{c}35.0 \\
\mid \\
23.3\end{array}$ & $\begin{array}{c}33.5 \\
\mid \\
21.8\end{array}$ & $\begin{array}{c}29.8 \\
\mid \\
21.8\end{array}$ & $\begin{array}{c}36.6 \\
\text { I } \\
23.5\end{array}$ & $\begin{array}{c}27.3 \\
\mid \\
16.5\end{array}$ & $\begin{array}{c}29.6 \\
\text { I } \\
22.2\end{array}$ & $\begin{array}{c}34.8 \\
\mid \\
22.6\end{array}$ & $\begin{array}{c}23.6 \\
\text { । } \\
5.2\end{array}$ & $\begin{array}{c}28.4 \\
\text { I } \\
22.8\end{array}$ & $\begin{array}{c}32.5 \\
\mid \\
23.9\end{array}$ & $\begin{array}{c}19.5 \\
\mid \\
7.6\end{array}$ \\
\hline $\mathrm{T}_{\text {night }}\left[{ }^{\circ} \mathrm{C}\right]^{3}$ & $\begin{array}{c}25.1 \\
\text { । } \\
20.0\end{array}$ & $\begin{array}{c}26.1 \\
\mid \\
20.9\end{array}$ & $\begin{array}{c}28 \\
\text { I } \\
18.0\end{array}$ & $\begin{array}{c}26.6 \\
\text { । } \\
20.9\end{array}$ & $\begin{array}{c}26.8 \\
\mid \\
21.5\end{array}$ & $\begin{array}{c}21.4 \\
\text { । } \\
12.6\end{array}$ & $\begin{array}{c}25.5 \\
\text { । } \\
21.2\end{array}$ & $\begin{array}{c}26.0 \\
\mid \\
21.1\end{array}$ & $\begin{array}{c}17.3 \\
\mid \\
2.6\end{array}$ & $\begin{array}{c}24.4 \\
\text { I } \\
21.7\end{array}$ & $\begin{array}{c}25.2 \\
\text { I } \\
22.4\end{array}$ & $\begin{array}{c}14.3 \\
\text { I } \\
4.6\end{array}$ \\
\hline $\mathrm{VPD}_{\max }[\mathrm{kPa}]^{4}$ & $\begin{array}{c}0.49 \\
\mid \\
0.25\end{array}$ & $\begin{array}{c}2.01 \\
\mid \\
0.90\end{array}$ & $\begin{array}{c}4.34 \\
\text { I } \\
2.2\end{array}$ & $\begin{array}{c}1.43 \\
\mid \\
0.29\end{array}$ & $\begin{array}{c}3.21 \\
1.59\end{array}$ & $\begin{array}{c}3.30 \\
\mid \\
1.98\end{array}$ & $\begin{array}{c}2.25 \\
\mid \\
0.73\end{array}$ & $\begin{array}{c}2.49 \\
\mid \\
1.13\end{array}$ & $\begin{array}{c}2.62 \\
\mid \\
0.36\end{array}$ & $\begin{array}{c}1.82 \\
\mid \\
0.51\end{array}$ & $\begin{array}{c}1.71 \\
\mid \\
0.74\end{array}$ & $\begin{array}{c}2.00 \\
\mid \\
0.60\end{array}$ \\
\hline $\operatorname{PAR}\left[\mu \mathrm{mol} \mathrm{m}^{-2} \mathrm{~s}^{-1}\right]^{5}$ & 135 & 1033 & 1685 & 75 & 673 & 1479 & 52 & 395 & 1016 & 59 & 474 & 1274 \\
\hline
\end{tabular}

29

30

31

32

33

34

35

36

37

${ }^{1}$ Understory (Und) heights are equivalent to water Zones 1 and 2 in Figure S3; canopy (Can) equivalent to Zones 3 and 4; Out are the outside values.

${ }^{2}$ Day-time temperature $10^{\text {th }}$ (bottom) and $90^{\text {th }}$ (top) percentile quantiles. Day-time hours are when outside PAR is greater than $10 \mu \mathrm{moles} \mathrm{m}^{-2} \mathrm{~s}^{-1}$. ${ }^{3}$ Night-time temperature $10^{\text {th }}$ and $90^{\text {th }}$ percentile quantiles. Night-time hours are when outside PAR is lower than $10 \mu \mathrm{moles} \mathrm{m}^{-2} \mathrm{~s}^{-1}$.

${ }^{4}$ Maximum vapor pressure deficit (VPD) 10 $0^{\text {th }}$ and $90^{\text {th }}$ percentile quantiles were based on the mean between 13:00 and 15:30.

${ }^{5}$ Maximum photosynthetically active radiation (PAR) was based on the mean between 11:00 and 14:30. 
Table S6. Plant analyses. Leaf chambers were located on instrument stream 1 (S1), stream 2 (S2), or stream 7 (S7). Functional grouping of individual plants is listed in Table S1. For CF 3 and 4, two sap flow sensors were installed per tree (CF3a,b and CF4a,b).
Ceiba

pentandra

Hibiscus

tiliaceus

Hura

crepitans

Pachira

aquatica

Phytolacca

dioica

\begin{tabular}{|c|c|}
\hline & PA3 \\
\hline & PA4 \\
\hline & PA6 \\
\hline & PA7 \\
\hline hytolacca & PD1 \\
\hline & PD2 \\
\hline & PD3 \\
\hline & PD4 \\
\hline Hibiscus rosa & HR1 \\
\hline & HR2 \\
\hline & HR3 \\
\hline & HR4 \\
\hline Piper sp. & PI1 \\
\hline & PI2 \\
\hline & PI3 \\
\hline & PI4 \\
\hline
\end{tabular}

Costus sp.

$\mathrm{CO} 1-4$

HT1

HC1

PA2

PA3

PA4

PA7

CP1

TT1

C1

\section{Leaf} chambers

Plant
ID

F3a

CF4a

CF4b

Bulk leaf
$\delta^{13} \mathrm{C}$
values

Leaf water potential
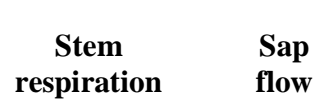

Stem

respiration

flow

water content

$\begin{array}{lll}* & * & * \\ * & * & * \\ * & * & * \\ * & * & * \\ * & * & *\end{array}$

$* \quad *$

$\mathrm{S} 2$

S2

S2

S2

S2

S2

S1

S2

S2

S2

$\mathrm{S} 2$

S2 
DIAAAS

Table S7. Instruments streams and analyzers on each stream.

59

\begin{tabular}{|c|c|c|c|c|c|c|c|}
\hline Stream & Analytes & $\begin{array}{l}\text { Analyzer } \\
\text { type-No. }\end{array}$ & Model & Manufacturer & Specifications & $\begin{array}{l}\text { Ecosystem } \\
\text { compartment }\end{array}$ & Calibration \\
\hline S1 & $\begin{array}{l}\mathrm{H}_{2} \mathrm{O}, \quad \mathrm{HDO}, \\
\mathrm{H}_{2}{ }^{18} \mathrm{O}, \mathrm{CO}_{2} \\
{ }^{13} \mathrm{CO}_{2} \\
\mathrm{CO}^{18} \mathrm{O}\end{array}$ & LAS-1 5 & $\begin{array}{l}\text { TILDAS }^{1} \text { dual } \mathrm{CO}_{2} \\
\mathrm{H}_{2} \mathrm{O} \text { isotope } \\
\text { analyzer }\end{array}$ & $\begin{array}{l}\text { Aerodyne Research } \\
\text { Inc., Billerica, MA, } \\
\text { USA }\end{array}$ & & $\begin{array}{l}\text { Atmosphere ( } 5 \\
\text { heights, TRF inlet), } \\
\text { leaf fluxes ( } 4 \\
\text { individuals \& } 1 \\
\text { blank) }\end{array}$ & CCU, LAS-2 \\
\hline S1 & BVOCs & MS-1 & PTR-QiToF-MS ${ }^{2}$ & $\begin{array}{l}\text { Ionicon Analytik } \\
\mathrm{GmbH} \text {, Austria }\end{array}$ & $\begin{array}{l}\text { drift tube P: } 3.8 \text { mbar; } \\
\text { drift tube T: } 80^{\circ} \mathrm{C} \\
\text { drift tube } \mathrm{U}: 847 \mathrm{~V} \\
\text { inlet T: } 80^{\circ} \mathrm{C} \\
\text { dwell time: } \\
\text { E/N: } 120 \mathrm{Td}\end{array}$ & & LCU \\
\hline $\mathrm{S} 2$ & $\begin{array}{l}\mathrm{CO}_{2} \\
{ }^{13} \mathrm{CO}_{2} \\
\mathrm{CO}^{18} \mathrm{O}\end{array}$ & LAS-2 & Delta Ray IRIS ${ }^{3}$ & $\begin{array}{l}\text { Thermo Fisher } \\
\text { Scientific, Bremen }\end{array}$ & $\begin{array}{l}\text { with Universal } \\
\text { Reference Interface }\end{array}$ & $\begin{array}{l}\text { Atmosphere ( } 2 \\
\text { heights), } \\
\text { leaf fluxes ( } 19 \\
\text { individuals \& } 1 \\
\text { empty chamber) }\end{array}$ & Internal \\
\hline $\mathrm{S} 2$ & $\begin{array}{l}\mathrm{H}_{2} \mathrm{O}, \quad \mathrm{HDO}, \\
\mathrm{H}_{2}{ }^{18} \mathrm{O}\end{array}$ & LAS-3 & L2120i & $\begin{array}{l}\text { Picarro Inc., Santa } \\
\text { Clara, CA, USA }\end{array}$ & & & $\begin{array}{l}\text { Intercomparison } \\
\text { with LAS-1; } \\
\text { laboratory } \\
\text { calibration for } \\
\text { concentration } \\
\text { dependency }\end{array}$ \\
\hline S2 & BVOCs & MS-2 & $\begin{array}{l}\text { PTR-TOF-MS } 4000 \\
\text { ultra }\end{array}$ & $\begin{array}{l}\text { Ionicon Analytik, } \\
\text { Austria }\end{array}$ & $\begin{array}{l}\text { drift tube pressure: } \\
2.7 \mathrm{mbar} ; \mathrm{E} / \mathrm{N} 108 \mathrm{Td}\end{array}$ & & LCU \\
\hline S3 & $\begin{array}{l}\mathrm{CO}_{2} \\
{ }^{13} \mathrm{CO}_{2} \\
\mathrm{CO}^{18} \mathrm{O}\end{array}$ & LAS-4 & G2201i & Picarro Inc. & $\begin{array}{l}\text { Interfaced with LI- } 8100 \\
\text { and LI-8150 16-port } \\
\text { multiplexer }\end{array}$ & $\begin{array}{l}\text { Soil fluxes, } 12 \\
\text { chambers }\end{array}$ & $\mathrm{CCU}$ \\
\hline S3 & BVOCs & MS-3 & PTR-TOF-MS ${ }^{4} 8000$ & $\begin{array}{l}\text { Ionicon Analytik } \\
\mathrm{GmbH} \text {, Austria }\end{array}$ & $\begin{array}{l}\text { drift tube P: } 2.2 \mathrm{mbar} \text {; } \\
\text { drift tube T: } 60{ }^{\circ} \mathrm{C} \\
\text { drift tube } \mathrm{U}: 600 \mathrm{~V} \\
\text { inlet T: } 60{ }^{\circ} \mathrm{C} \\
\text { dwell time: } 10 \mathrm{~s} \\
\text { E/N: } 137 \mathrm{Td}\end{array}$ & $\begin{array}{l}\text { Soil VOC fluxes, } 12 \\
\text { chambers }\end{array}$ & LCU \\
\hline S5 & $\begin{array}{l}\mathrm{CO}_{2} \\
{ }^{13} \mathrm{CO}_{2}\end{array}$ & LAS-5 & G2131i & Picarro Inc. & & Stem fluxes, 12 trees & $\mathrm{CCU}$, internal \\
\hline S7 & $\begin{array}{l}\mathrm{H}_{2} \mathrm{O}, \quad \mathrm{HDO}, \\
\mathrm{H}_{2}{ }^{18} \mathrm{O}\end{array}$ & LAS-6 & L2130-i & Picarro Inc. & & $\begin{array}{l}\text { Leaf fluxes ( } 4 \\
\text { individuals \& } 1 \\
\text { empty chamber) }\end{array}$ & $\mathrm{CCU}$ \\
\hline
\end{tabular}

$60 \quad{ }^{1}$ Tunable Infrared Laser Direct Absorption Spectroscopy

$61{ }^{2}$ Proton Transfer Reaction Quadrupole Ion guide Time Of Flight Mass Spectrometer

$62{ }^{3}$ Isotope Ratio Infrared Spectrometer

63 Proton Transfer Reaction Time Of Flight Mass Spectrometer

$64 \quad{ }^{5}$ LAS: Laser Absorption Spectrometer

65 MS: Mass Spectrometer, here referring to PTR-TOF-MS moieties

66 
Table S8. VOC gas standard for daily explicit calibration and transmission calculation

\begin{tabular}{|c|c|c|c|}
\hline Compound & Chemical Formula & $\begin{array}{l}\text { Concentration } \\
\text { Cylinder } 1 \text { [ppbV] }\end{array}$ & $\begin{array}{l}\text { Concentration } \\
\text { Cylinder } 2 \text { [ppbV] }\end{array}$ \\
\hline Methanol & $\mathrm{CH}_{3} \mathrm{OH}$ & 494 & 433 \\
\hline Acetonitrile & $\mathrm{C}_{2} \mathrm{H}_{3} \mathrm{~N}$ & 487 & 461 \\
\hline Ethanol & $\mathrm{C}_{2} \mathrm{H}_{5} \mathrm{OH}$ & 504 & 0 \\
\hline Propanal & $\mathrm{C}_{3} \mathrm{H}_{6} \mathrm{O}$ & 0 & 463 \\
\hline Acetone & $\mathrm{C}_{3} \mathrm{H}_{6} \mathrm{O}$ & 497 & 0 \\
\hline Isoprene & $\mathrm{C}_{5} \mathrm{H}_{8}$ & 509 & 0 \\
\hline DMS & $\mathrm{C}_{2} \mathrm{H}_{6} \mathrm{~S}$ & 537 & 0 \\
\hline Methacrolein & $\mathrm{C}_{4} \mathrm{H}_{6} \mathrm{O}$ & 252 & 0 \\
\hline Methyl Vinyl Ketone & $\mathrm{C}_{4} \mathrm{H}_{6} \mathrm{O}$ & 243 & 0 \\
\hline Benzene & $\mathrm{C}_{6} \mathrm{H}_{6}$ & 510 & 497 \\
\hline Toluene & $\mathrm{C}_{7} \mathrm{H}_{8}$ & 489 & 0 \\
\hline Furfural & $\mathrm{C}_{5} \mathrm{H}_{4} \mathrm{O}_{2}$ & 479 & 0 \\
\hline Hexanal & $\mathrm{C}_{6} \mathrm{H}_{12} \mathrm{O}$ & 0 & 494 \\
\hline Styrene & $\mathrm{C}_{8} \mathrm{H}_{8}$ & 0 & 498 \\
\hline$m$-Xylene & $\mathrm{C}_{8} \mathrm{H}_{10}$ & 0 & 499 \\
\hline Acetophenone & $\mathrm{C}_{8} \mathrm{H}_{8} \mathrm{O}$ & 0 & 496 \\
\hline$p$-Isopropyltoluene & $\mathrm{C}_{10} \mathrm{H}_{14}$ & 0 & 474 \\
\hline$\alpha$-Pinene & $\mathrm{C}_{10} \mathrm{H}_{16}$ & 0 & 126 \\
\hline$\beta$-Pinene & $\mathrm{C}_{10} \mathrm{H}_{16}$ & 0 & 125 \\
\hline 3-Carene & $\mathrm{C}_{10} \mathrm{H}_{16}$ & 0 & 143 \\
\hline Limonene & $\mathrm{C}_{10} \mathrm{H}_{16}$ & 0 & 148 \\
\hline Linalool & $\mathrm{C}_{10} \mathrm{H}_{18} \mathrm{O}$ & 466 & 0 \\
\hline$\alpha$-Cedrene & $\mathrm{C}_{15} \mathrm{H}_{24}$ & 105 & 189 \\
\hline Hexamethylcyclotrisiloxane (D3) & $\mathrm{C}_{6} \mathrm{H}_{18} \mathrm{O}_{3}$ & 502 & 509 \\
\hline Octamethylcyclotetrasiloxane (D4) & $\mathrm{C}_{8} \mathrm{H}_{24} \mathrm{O}_{4}$ & 502 & 499 \\
\hline Decamethylcyclopentasiloxane (D5) & $\mathrm{C}_{10} \mathrm{H}_{30} \mathrm{O}_{5}$ & 518 & 498 \\
\hline Dodecamethylcyclohexasiloxane (D6) & $\mathrm{C}_{12} \mathrm{H}_{36} \mathrm{O}_{6}$ & 190 & 0 \\
\hline
\end{tabular}

